\title{
Investigation on hard turning temperature under a novel pulsating MQL environment: An experimental and modelling approach
}

\author{
Soumikh Roy, Ramanuj Kumar*, Ashok Kumar Sahoo, Anish Pandey, and Amlana Panda \\ School of Mechanical Engineering, KIIT University, Bhubaneswar-24, Odisha, India
}

Received: 20 May 2020 / Accepted: 27 September 2020

\begin{abstract}
Generation of total heat in hard turning largely influenced the cutting tool wear, tool life and finishing quality of work-surface. Thus, the measurement of this heat in terms of temperature becomes a necessity for achieving favourable machining performances. Therefore, this work presents a novel study on temperature measurement in three different zones during hard turning operation of 4340 grade steel under pulsating MQL environment. Temperatures are measured at three different locations namely chip-tool interface, flank face, and machined work surface (near to tool-work contact) and the location wise temperature is termed as chip tool interface temperature (T), flank face temperature (Tf) and machined work surface temperature (Tw) correspondingly. The temperature $\mathrm{T}$ and $\mathrm{Tf}$ are measured with help of K-type thermocouple while $\mathrm{Tw}$ is measured by Fluke make infra-red thermal camera. Pulsating MQL significantly reduced the temperature as the maximum temperature is noticed $110^{\circ} \mathrm{C}$ which corresponds to chip-tool interface temperature $(\mathrm{T})$ at highest speed $(200 \mathrm{~m} / \mathrm{min})$ condition. In each test, the order of temperature follow the trend as: $\mathrm{T}>\mathrm{Tf}>\mathrm{Tw}$. Considering average of all 16 temperatures, $\mathrm{T}$ is $14.42 \%$ greater than $\mathrm{Tf}$ and $39.36 \%$ larger than $\mathrm{Tw}$ while $\mathrm{Tf}$ is $21.79 \%$ greater than Tw. Experimental results concludes that the cutting speed is the most influencing factor followed by depth of cut for both $\mathrm{T}$ and Tf, whereas depth of cut is the most influencing factor for Tw. Further, these temperatures are predicted using linear regression, and absolute mean error (MAE) for responses T, Tf, and $\mathrm{Tw}$ is noticed as $1.848 \%, 0.542 \%$, and $3.766 \%$ individually. Additionally, the optimum setting of input terms are estimated using WPCA (weighted principal component analysis) and found to be $d c_{1}(0.1 \mathrm{~mm})-f r_{2}$ $(0.08 \mathrm{~mm} / \mathrm{rev})-v c_{2}(100 \mathrm{~m} / \mathrm{min})-P t_{2}(2 \mathrm{~s})$
\end{abstract}

Keywords: Hard turning / pulsating MQL / temperature / linear regression / WPCA

\section{Introduction}

Nowadays machining operation has become the most commonly used manufacturing technique in every corner of the world. It is one of the most commonly used manufacturing process in which the desired dimension and surface quality of the product is being achieved by removal of unwanted materials from the work-piece in the form of chips. As the cutting tool makes contact with the metal it induces shear type deformation within the metal and it starts moving upward along rake surface of the cutting tool [1]. Turning operation conducted over a workpiece with hardness greater than $45 \mathrm{HRC}$ is known as hard turning operation [2]. In present day the hard turning operation is preferred over costly grinding operation because of its simplicity in machining operation and higher production rate. Turning operation under dry cutting exhibited greater extent of temperature which promotes

\footnotetext{
* e-mail: ramanujkumar22@gmail.com
}

the larger tooling wear rate thus lower life span of tool, poor quality of finish and larger dimensional deviation [3-5]. Therefore, nowadays controlling the temperature in hard turning problems is major challenge. To counter the above problems, many researchers have tried to utilize various cooling techniques such as flooded cooling, high-pressure jet cooling, minimum quantity lubrication environments, spray impingement cooling, cryogenic cooling, etc. As compared to other cooling techniques, the performance of minimum quantity lubrication (MQL) was found efficient and economical. In MQL, a very less amount of concentrated coolant is sprayed over the machining zone which attributed the higher heat dissipation efficiency as compared to other cooling environments. The MQL coolant penetration is excellent due to high injection pressure of around 2-8 Bar. Also, because of lower amount of coolant consumption during MQL technique, the coolant cost and coolant handling cost greatly reduced and favours the economical machining. However, all this advantageous features of MQL makes it a worthy contender in the race for better alternative over dry machining condition [6-8]. 
Currently, researchers are giving more emphasize on the enhancement in the performance of MQL by controlling the air pressure, rate of coolant flow and pulse time. In MQL, interrupt flow of coolant by varying the pulse time exhibited an additional augmentation in rate of heat transfer compared to continuous flow [9-10]. The technique of interrupt flow of coolant in MQL is named as pulse MQL technique. Pulsating supply of coolant through MQL reduces the coolant consumption over conventional MQL thus provide an economic and ecological machining. According to Mia et al. [9], 1-s pulse time exhibited the enhanced quality of finish surface compared to 3-s and 5-s pulse time in MQL turning process. Similarly, Bashir et al. [11] stated that the pulse jet MQL extensively retard the cutting force and enhance the cutting tool performance relative to dry cutting.

Further, characteristics of coolant/lubricant considerably influence the machining attributes and working surrounding. As per recent study, use of conventional fluids is hazardous for the human health as well as environment and very difficult for its disposal which adds extra manufacturing cost. It is also noted that yearly in the United States, 155 million gallons of cutting fluids are released into the surroundings [12]. Therefore to overcome these challenges researchers are taking keen interest in ecofriendly cutting fluids as a better substituent of conventional cutting fluids. Many eco-friendly lubricants such as iron aluminium oil, coconut oil, sunflower oil, castor oil, rapeseed oil, carona oil etc. are used as cutting fluids. Researchers have also recommended the use of nano particle bases cutting fluid and water soluble cutting oil as the better option over traditional cutting fluids [3,13]. Das et al. [14] experimentally found that MQL assisted operation using eco-friendly $\mathrm{Al}_{2} \mathrm{O}_{3}$ enriched nano fluid performs better as compared to both water soluble coolant and compressed air. Gunjal et al. [15] compared the effect of different eco-friendly cutting fluid on machining performance during MQL assisted turning operation. The performance of coconut oil is superior over soybean oil and canola oil. Das et al. [16] compared the performance of various coolant/lubricant under MQL cooling environment during turning operation of grade 4340 steel. Heat dissipation capability of nanofluid was found superior to that of compressed air and water soluble coolant.

From the metal cutting mechanics, it can be stated that the cutting temperature is the prime agent which majorly influence the tooling wear and surface finish [17]. High machining temperature increases the rate of tool wear thus shorten the life of the tool. It also causes the thermal deformation of both the tool and workpiece. At high machining temperature there is also degradation in surface quality of the finished product and there are also huge chances of residual stress and white layer formation at the subsurface of the finished workpiece. The prediction of heat distribution and heat intensity is very difficult due to the complexity of heat transfer mechanism during machining operation. Thus, it becomes very necessary and challenging to measure the heat intensity and amount of heat generated during a machining operation $[18,19]$.

Many researchers have worked on temperature analysis during turning process with help of thermocouple and infrared thermography/pyrometer [20]. O'Sullivan and Cotterell [20] used two embedded thermocouple inside the hollow workpiece to study the role of cutting speed on machining temperature and cutting forces. Cutting forces magnitude was dropping while machining temperature was increasing with leading speed. Basti et al. [21] utilized a thin film thermocouple sensors to measures the machining temperature. Chinchanikar et al. [22] developed a toolworkpiece thermocouple principle based model to study the machining temperature at chip tool interface during turning operation of grade 4340 steel and observed that the machining temperature was primarily dependent on machining speed trailed by feed rate. Kus et al. [23] measured the tool temperature during turning operation of grade 4340 steel by implementation of infrared radiation pyrometer and $\mathrm{K}$ type thermocouple. Chen et al. [24] measured machining temperature during turning operation using embedded thermocouple in both tool and workpiece. Machining temperature at the rake face of the tool was found significantly higher than flank face. Leshock and Shin [25] utilized cutting tool workpiece thermocouple technique to measure the machining temperature during turning operation. Machining temperature exhibited a noteworthy consequence on the volume of crater wear formation. Machining temperature as well as feed was the noteworthy agents towards elevating the magnitude of machining temperature. Hadad et al. [26] studied the machining temperature and energy partition in MQL grinding operation by implementing embedded thermocouple technique. The energy participation and machining zone temperature were found dependent on the type of lubricant/coolant conditions and abrasives. Santos Jr. et al. [27] studied the effect of thermoelectric junctions on electrical signals produced by the machining tool-workpiece thermocouple system during turning operation. Electrical signal generated at the chip-tool interface zone provided machining temperature data which provided concrete evidence that machining temperature is primarily dependent on cutting speed and feed. Huda et al. [28] developed a tool-chip interface temperature measurement technique by using two different colour pyrometers during turning operation under different cooling environment and traced that the cutting temperature is the predominant factor for tool chip interface temperature. Reduction in cutting temperature by $30^{\circ} \mathrm{C}$ was obtained under overhead jet cooling as compared to dry machining condition. Kumar et al. [29-31] utilized infrared thermal imager in machining of D2 steel under dry, air-water spray impingement cooling and water based nanofluid spray impingement cooling. Cutting speed and depth of cut were the leading cutting agents which were influencing cutting temperature most.

Based on the literature studied, MQL gain a significant attention by the researcher and successfully implemented in hard metal machining sector. Very few research works were conducting under pulsating MQL (PMQL) environment and mostly concluded that the PMQL performance was superior over normal MQL. Lots of works were considered the temperature analysis under MQL scenario but temperature analysis in PMQL scenario is rarely available. In fact, in MQL mostly work reported the analysis of tool-chip interface or rake surface temperature. 


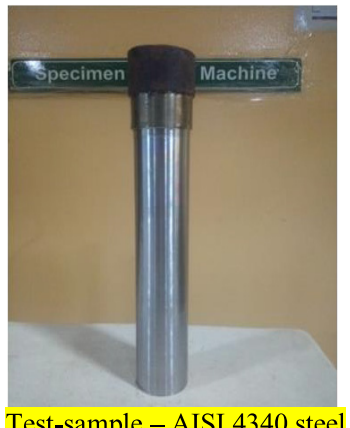

\begin{tabular}{|c|c|}
\hline \multicolumn{2}{|c|}{ Chemical structure of 4340 steel } \\
\hline Elements & Weight $\%$ \\
\hline $\mathrm{Cr}$ & 0.906 \\
\hline $\mathrm{Mn}$ & 0.887 \\
\hline $\mathrm{C}$ & 0.374 \\
\hline $\mathrm{Si}$ & 0.313 \\
\hline $\mathrm{S}$ & 0.010 \\
\hline $\mathrm{P}$ & 0.042 \\
\hline $\mathrm{Cu}$ & 0.021 \\
\hline $\mathrm{Ni}$ & 0.107 \\
\hline $\mathrm{Fe}$ & Balance \\
\hline
\end{tabular}

\begin{tabular}{|l|c|}
\hline \multicolumn{2}{|c|}{$\begin{array}{c}\text { Mechanical properties of } \\
4340 \text { steel }\end{array}$} \\
\hline Yield stress & $950 \mathrm{MPa}$ \\
\hline Hardening modulus & $730 \mathrm{MPa}$ \\
\hline Young's modulus & $205 \mathrm{GPa}$ \\
\hline Bulk modulus & $140 \mathrm{GPa}$ \\
\hline Shear modulus & $80 \mathrm{GPa}$ \\
\hline Poisson's ratio & 0.3 \\
\hline Rockwell hardness & $50 \pm 1 \mathrm{HRC}$ \\
\hline
\end{tabular}

Fig. 1. Test-sample with its chemical structure and mechanical properties.

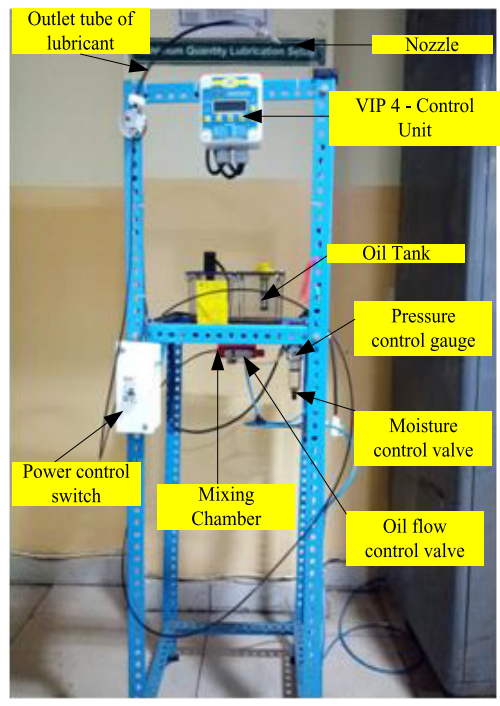

(a)

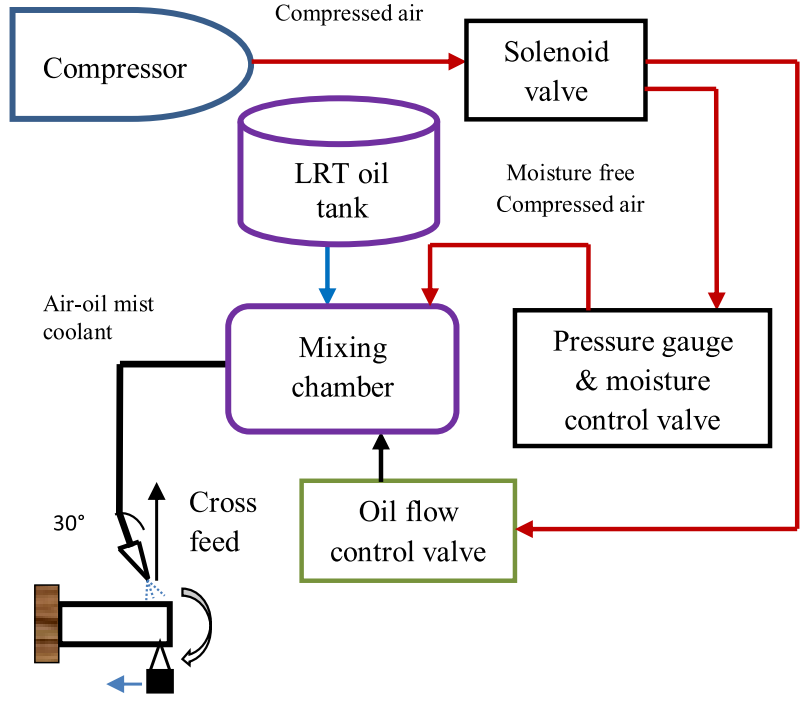

(b)

Fig. 2. (a) Pulsating MQL system (b) Lubricant flow direction of Pulsating MQL system.

But flank face temperature is rarely carried. Therefore, this work presented a novel study on cutting temperature measurement in hard turning of most popular hard metal 4340 steel under pulsating MQL surrounding. Temperature was measured in three different locations namely work-tool contact temperature (by using infra-red thermography), tool-rake temperature (using thermocouple) and flank face temperature near to wear zone (using thermocouple). Further, these temperatures are predicted using linear regression, fuzzy logic and ANN approaches.

\section{Experimental Details and procedure}

\subsection{Test-sample material and cutting tool}

The test-sample used for finish hard turning is heat treated AISI 4340 grade steel and their average hardness is $50 \pm 1$ HRC. AISI 4340 grade steel is an alloy of molybdenumnickel- chromium and known for its high toughness with greater hardness strength even at extreme temperature. Also, it hold good fatigue resistance, high wear resistance, greater corrosion resistance and superior strength.
The test-sample with its chemical structure and mechanical properties are shown in Figure 1. WIDIA make MT CVD multilayer coated $\left(\mathrm{TiN} / \mathrm{TiCN} / \mathrm{Al}_{2} \mathrm{O}_{3}\right)$ carbide insert with ISO geometry CNMG 120408 with P-grade (TN-5105) in normal condition was utilized for turning experiments. The geometry of tool is as follows: clearance angle $=5^{\circ}$, back rake angle $=-6^{\circ}$, included angle $=80^{\circ}$, approach angle $=95^{\circ}$ and tool-nose radius $=0.8 \mathrm{~mm}$.

\subsection{Pulsating MQL system}

Pulse MQL is an advanced version of MQL. MQL corresponds to the steady flow of coolant/lubricant while in pulse MQL flow of coolant/lubricant is controlled through time-controlled i.e. the coolant/lubricant flow is not continuous; it fluctuates with respect to the time gap between two consequent pulses of the jet.

DROPSA (Italy) supplied industrial grade MQL system is utilized for deliver the compressed air-lubricant mist sprayed form into cutting region. The MQL set-up and its flow chart are displayed in Figure $2 \mathrm{a}$ and $2 \mathrm{~b}$ consequently. The flow of air and lubricant is clearly mention in the schematic flow diagram (Fig. 2b), initially 
Table 1. Machining conditions during the experiment.

\begin{tabular}{ll}
\hline Machining condition & Description \\
\hline Machine tool & CNC lathe (Jyoti India Pvt. Ltd.) \\
Test sample & AISI 4340 grade steel $(50 \mathrm{HRC})$ \\
Test sample diameter & $38 \mathrm{~mm}$ \\
Cutting length & $175 \mathrm{~mm}$ \\
& $\mathrm{TiN} / \mathrm{TiCN} / \mathrm{Al}_{2} \mathrm{O}_{3}$ coated carbide (CVD) \\
Plan of experiments & $\mathrm{L}_{16}$ \\
Cutting speed & $50,100,150$ and $200 \mathrm{~m} / \mathrm{min}$ \\
Feed rate & $0.04,0.08,0.12$ and $0.16 \mathrm{~mm} / \mathrm{rev}$ \\
Depth of cut & $0.1,0.2,0.3$ and $0.4 \mathrm{~mm}$ \\
Pulse time & $1,2,3,4 \mathrm{~s}$ \\
Cutting surroundings & Pulse MQL \\
Lubricant & LRT 30 (supplied by Dropsa) \\
Response & Chip tool interface temperature (T), flank face temperature (Tf) and machined \\
& work surface temperature (Tw). \\
\hline
\end{tabular}

compressed air was entered into the solenoid valve and then it is supplied into the moisture control valve via air pressure control valve and oil control valve. Further, moisture free compressed air entered into the mixing chamber. In other side, by gravity mode, lubricating oil is entered into mixing chamber from oil tank. The purpose of supplying air into mixing chamber is to provide proper mixing of air and LRT 30 lubricant while the moisture free compressed air is supplied into flow control valve to deliver the mist lubricant into cutting zone using CH10 5/16 type spray nozzle. This set-up is being set at pulse mode to provide time controlled air-lubricant mist flow. Pulse time considerably affects the utilization of lubricant quantity. Coolant flow through pulse MQL system can be understand using the following example: if pulse time is $2 \mathrm{~s}$ then at every $2 \mathrm{~s}$ of interval, MQL will deliver the coolant continuously for $2 \mathrm{~s}$ and this process is repeated in cyclic manner. However, increasing pulse time reduces the utilization of coolant amount. To understand the importance of pulse time, the current work considers it as an input term. Four different levels of pulse time such as 1, 2, 3 , and $4 \mathrm{~s}$ are considered and the respective flow rates are estimated as 50, 25, 17, and $13 \mathrm{ml} /$ hour at constant air pressure of 5 bar. LRT 30 lubricant (commercial grade) is utilized as a cutting fluid due its several eco-friendly properties like non-toxic, non-polluting, non-flammable, non-blotting etc. Also, it is manufactured using innocuous constituents which providing outstanding lubrication properties. LRT 30 lubricant has viscosity at $40^{\circ} \mathrm{C}$ is $24 \mathrm{cSt}$, flammability limit is more than $220^{\circ} \mathrm{C}$ and specific weight at $15^{\circ} \mathrm{C}$ is $0.9 \mathrm{~kg} / \mathrm{l}$. Also, it has a decent anticorrosion characteristic which is beneficial against damage of machine tool parts [32]. During machining, the nozzle position of MQL is kept at $30^{\circ}$ from the cross feed direction and distance between contact zone (tool-tip and test specimen contact) and nozzle outlet point is kept fixed as $50 \pm 2 \mathrm{~mm}$.

\subsection{Machine tool and experimental design}

Machining tests were performed on a CNC lathe machine (Jyoti India Pvt. Ltd.) under pulse MQL environment. Taguchi $\mathrm{L}_{16}$ design is utilized to conduct the experiments. Four input variables like cutting speed (vc), feed (fr), depth of cutting (dc), and pulse time (Pt) are considered. Each input variable has four different levels and the details are located in Table 1. Source of temperature are studied at three different locations like chip tool interface temperature (T), flank face temperature (Tf) and machined work surface temperature (Tw).

\subsection{Details of temperature measurement}

During any machining process the machining temperature is one of the major factors which affect the machining performance. The surface quality, tool wears and tool life are directly influenced by machining temperature. So measurement of machining temperature becomes very important to achieve better machining performance. In this study, machined workpiece surface temperature, Tw (near to tool-work contact point) is measured using Fluke make infra-red thermal camera while, chip tool interface temperature $(\mathrm{T})$ and flank face (near to main cutting edge) temperature (Tf) are measured using K-type thermocouple and CHINO KR 2000 data acquisition system (DAS). The Fluke Ti-32 infrared camera and CHINO KR 2000 data acquisition system are shown in Figure $3 \mathrm{a}$ and $3 \mathrm{~b}$. The temperature measurement range of Fluke Ti-32 infrared camera lies in between $-20^{\circ} \mathrm{C}$ and $+600{ }^{\circ} \mathrm{C}[30]$. The infrared camera is operated at a distance of 12 to $15 \mathrm{~cm}$ from the tool-work contact zone. The K type thermocouple has the temperature range of $-195-1100^{\circ} \mathrm{C}$ [23]. It has a high melting point of $1400^{\circ} \mathrm{C}$. The calibration of the thermocouple was done using a multimeter at ice point $\left(0^{\circ} \mathrm{C}\right)$ and boiling point $\left(100^{\circ} \mathrm{C}\right)$ of water by 
measuring the voltage with the help of a thermocouple calibrator and the obtained voltage data was compared with standard K-type thermocouple temperature vs. voltage plot. The thermocouples and CHINO data

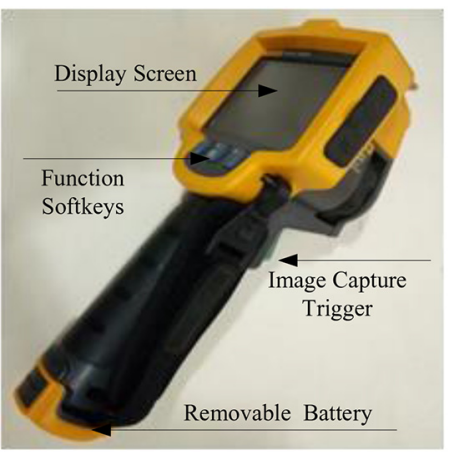

(a)

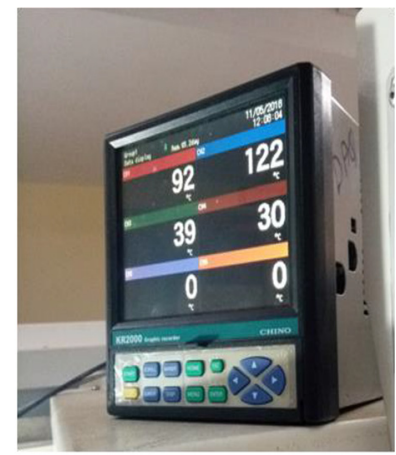

(b)
Fig. 3. (a) Fluke Ti 32 Infrared Camera (b) CHINO KR 2000 data acquisition system. acquisition system were also calibrated in similar way at ice point $\left(0^{\circ} \mathrm{C}\right)$ and boiling point $\left(100^{\circ} \mathrm{C}\right)$ of water. Similar calibration procedure of thermocouple was adopted by Ukamanal et al. [33]. The response time of thermocouple was noticed to be $300 \mu \mathrm{s}$.

Further, a hole (1 mm depth and $1 \mathrm{~mm}$ diameter) is created at the rake surface and principal flank face of the cutting insert using electrical discharge machining with copper electrode. The shortest distance between the centre of hole and cutting edges (principal cutting edge and auxiliary cutting edge) are kept the same as $1.5 \mathrm{~mm}$. The schematic view of the hole location and its dimensions are located in Figure 4. Further, one end of individual thermocouple was embedded in the respective hole of rake and flank surfaces as shown in Figure 5, while other end of thermocouple is being attached to the data acquisition system (DAS). A DAS is utilized to stores, collect and distribute the data information. In the present study, the data acquisition system is being used to record the temperature data with a frequency of $0.01 \mathrm{~s}$. Similar methods were adopted by several researchers [23,33-35].

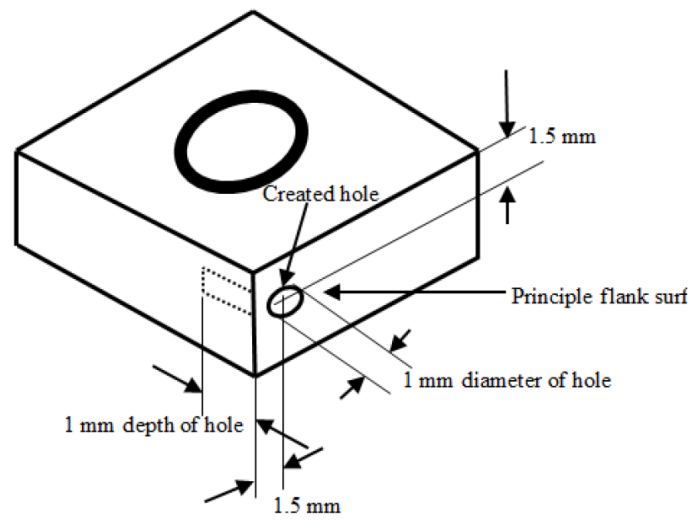

(a)

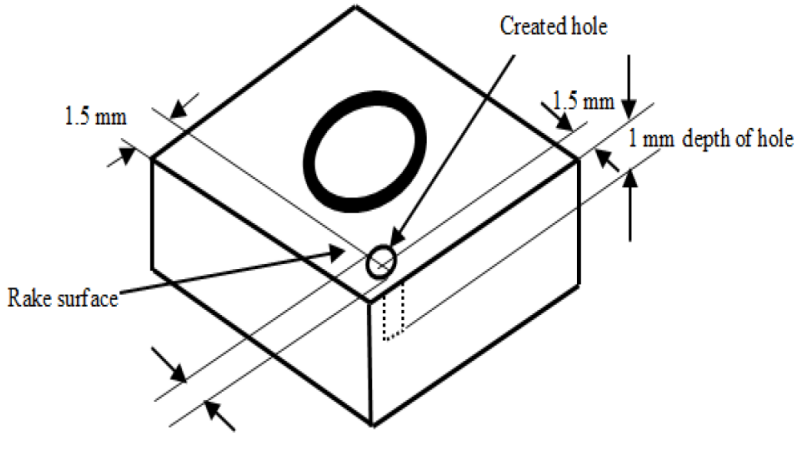

$1 \mathrm{~mm}$ diameter of hole

(b)

Fig. 4. Schematic view of dimension of hole created on tool (a) rake face (b) principal flank face.

Preparation of tool for Temperature study using thermocouple
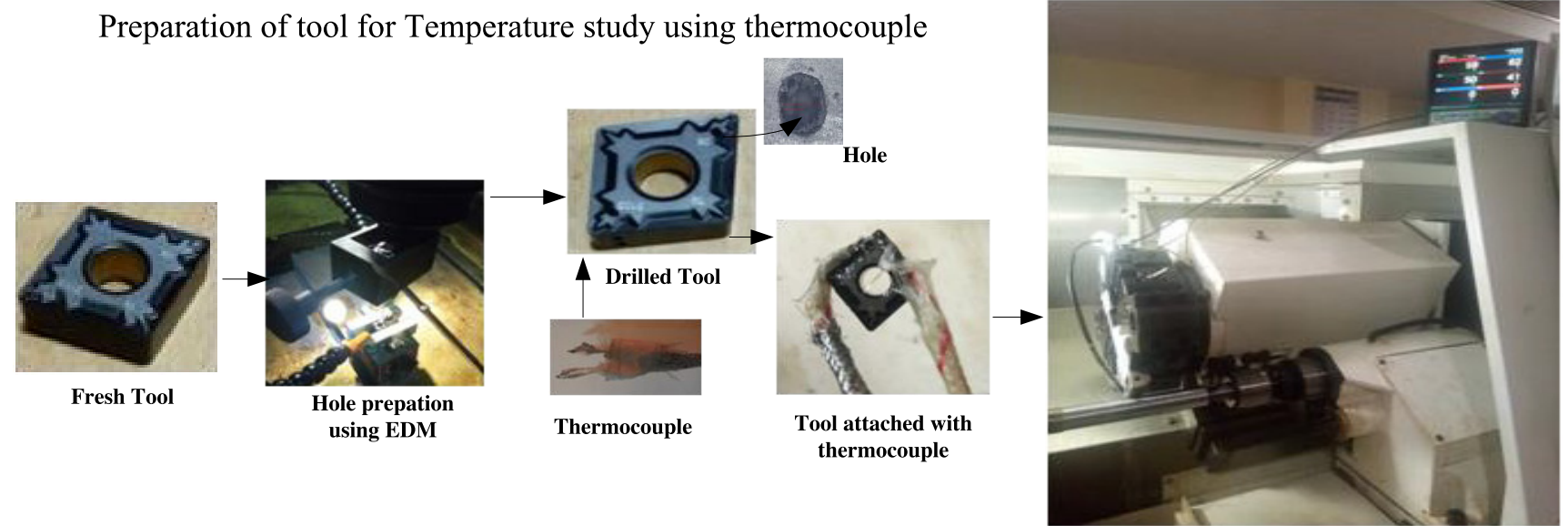

Turning operation under Pulsating MQL Environment

Fig. 5. Thermocouple arrangement and turning setup. 
Table 2. Measured results.

\begin{tabular}{|c|c|c|c|c|c|c|c|}
\hline Run No. & \multicolumn{4}{|c|}{$\mathrm{L}_{16}$ set of input parameters } & \multicolumn{3}{|c|}{ Response obtained (average value) } \\
\hline 1 & 0.1 & 0.04 & 50 & 1 & 83 & 71 & 44.6 \\
\hline 2 & 0.1 & 0.08 & 100 & 2 & 85 & 76 & 51.9 \\
\hline 3 & 0.1 & 0.12 & 150 & 3 & 96 & 82 & 56.5 \\
\hline 4 & 0.1 & 0.16 & 200 & 4 & 104 & 88 & 63.6 \\
\hline 6 & 0.2 & 0.08 & 50 & 4 & 92 & 78 & 58.1 \\
\hline 7 & 0.2 & 0.12 & 200 & 1 & 101 & 88 & 65.9 \\
\hline 8 & 0.2 & 0.16 & 150 & 2 & 96 & 85 & 62.8 \\
\hline 9 & 0.3 & 0.04 & 150 & 4 & 105 & 87 & 69.5 \\
\hline 10 & 0.3 & 0.08 & 200 & 3 & 110 & 90 & 89.8 \\
\hline 14 & 0.4 & 0.08 & 150 & 1 & 101 & 88 & 83.8 \\
\hline 15 & 0.4 & 0.12 & 100 & 4 & 96 & 89 & 85.3 \\
\hline 16 & 0.4 & 0.16 & 50 & 3 & 92 & 87 & 82.5 \\
\hline
\end{tabular}

According to Fluke infrared camera emissivity chart, the emissivity of steel varies from 0.8 to 0.9 . Hence, in the current work, the emissivity was taken as $85 \%$ i.e. 0.85 . The accuracy of Fluke Ti 32 camera and thermocouple CHINO $\mathrm{KR} 2000$ data acquisition is found as $\pm 2{ }^{\circ} \mathrm{C}$.

\subsection{Details of machining experiments and procedure}

The current turning operation was performed on heat treated 4340 steel using coated carbide insert and the machining length along the length of round bar is taken as $175 \mathrm{~mm}$. The initial dimension of workpiece as follows: $39 \mathrm{~mm}$ diameter and $200 \mathrm{~mm}$ length. To remove the rust from the workpiece, upper layer of material was removed by taking $0.5 \mathrm{~mm}$ of depth cut. Further, $15 \mathrm{~mm}$ length was used for holding the workpiece while $10 \mathrm{~mm}$ clearance has been kept for avoiding the contact of MQL nozzle with chuck. Therefore, the final working diameter is $38 \mathrm{~mm}$ and machining length is $175 \mathrm{~mm}$. Each turning test has been repeated 5 times. Each repeated test has been done using new cutting edge and the temperatures ( $\mathrm{T}$, Tf, and $\mathrm{Tw}$ ) are measured for each repeated experiments. The average value of temperature for each repeated experiments is considered and shown in Table 2. Also, considering the repeatability test data, the standard error is estimated and represented through Figure 6 . The average standard error for $\mathrm{T}$, Tf, and $\mathrm{Tw}$ are found as $\pm 1.64^{\circ} \mathrm{C}, \pm 1.53^{\circ} \mathrm{C}$, and $\pm 0.84^{\circ} \mathrm{C}$ respectively. The temperature data for chip-tool interface temperature $(\mathrm{T})$ and flank face temperature (Tf) are considered when temperature readings are almost steady and higher in range. The maximum temperature value of the work surface is considered as the machined work surface temperature for each run.

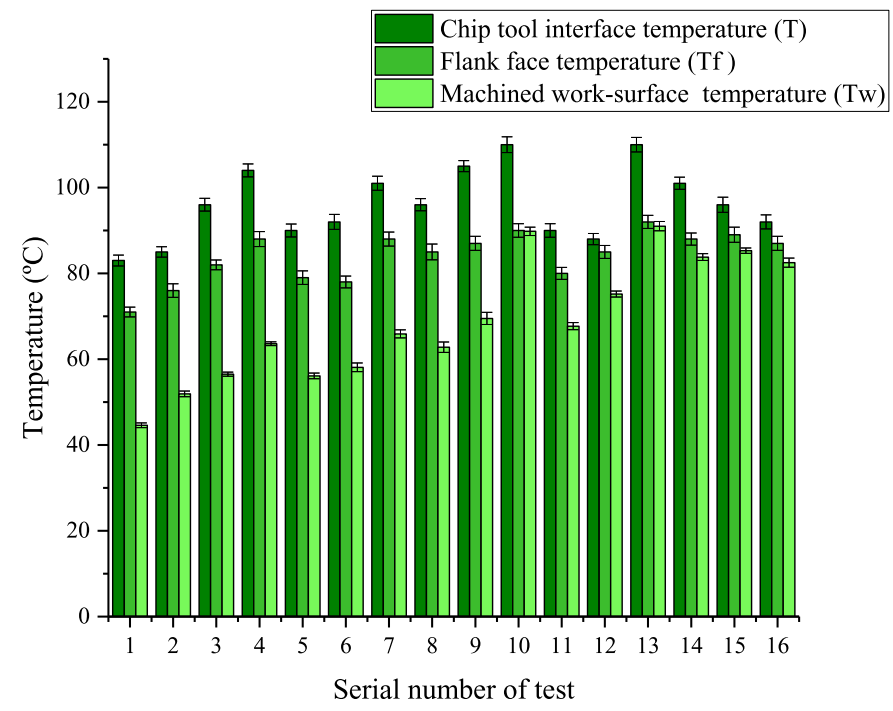

Fig. 6. Comparison between values of $\mathrm{T}$, Tf and $\mathrm{Tw}$.

\section{Result and discussion}

Temperature evolved during machining plays a vibrant role in hard machining and. It must be within a rational limit for avoiding certain complexities like the heat affected zone, plastic deformation of tool-edge, and larger tool wear, since it degrades the surface quality. Therefore, to understand the phenomena of temperature intensity, three different temperature such as chip tool interface temperature $(\mathrm{T})$, flank face temperature (Tf), and machined 


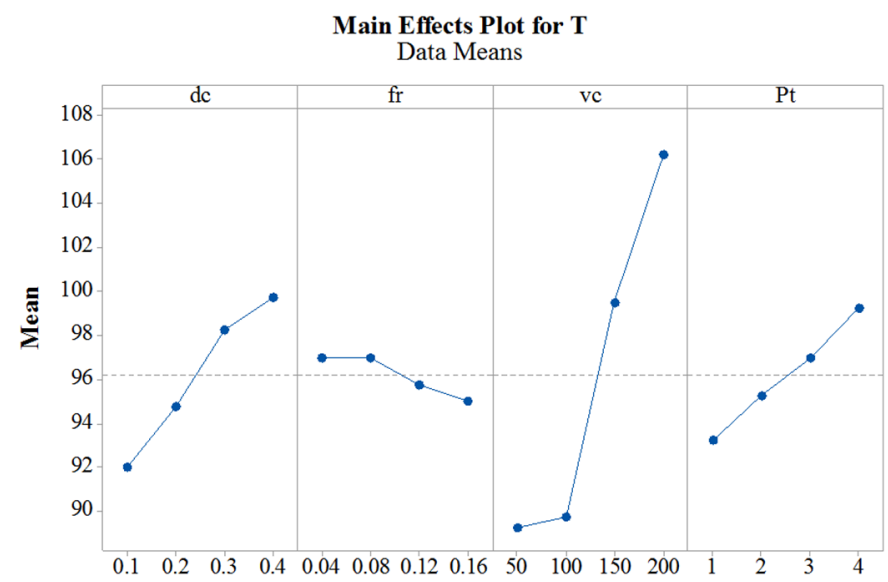

Fig. 7. Influence of input terms on $\mathrm{T}$.

work-surface temperature (Tw) are measured for each input setting of $\mathrm{L}_{16}$ experimental structure and located in Table 2. Further, a comparison graph between T, Tf and Tw is plotted for each test and indicated in Figure 6. All the distinct types of temperatures are noticed to be low due to surplus augmentation in heat transfer from the machining zone due to application of pulsating MQL. Also, frictional forces between interface surfaces are retarding under fluctuating mode of coolant supplied over interfacing surfaces. Similar findings were reported by many researchers [36-38]. In each test, chip-tool interface temperature is greater than flank face temperature and machined worksurface temperature. The trend of temperature for each test is noticed as: $\mathrm{T}>\mathrm{Tf}>\mathrm{Tw}$. Considering average of all 16 results for each response, chip-tool interface temperature is $14.42 \%$ greater than flank face temperature and $39.36 \%$ larger than machined work-surface temperature while flank face temperature is $21.79 \%$ greater than machined work-surface temperature.

\subsection{Inspection of chip tool interface temperature}

Chip tool interface temperature is one of the prime heat source affecting tool wear specially crater wear during cutting process. To measure this temperature, $\mathrm{K}$ type thermocouple is attached ( $1 \mathrm{~mm}$ from the tool-tip) on to the tool-rake face and through data acquisition arrangement readings are stored and collected. Average of five higher temperatures data is considered as the final chip tool interface temperature and shown in Table 2 and Figure 6. The chip tool interface temperature data found in range of $83-110^{\circ} \mathrm{C}$, which is quite low for finish hard turning concern. Chinchanikar and Choudhury [39] found $500-900^{\circ} \mathrm{C}$ temperature at chip tool interface in dry machining of 4340 steel. Getting the lower range values of temperature connoted the occurrence of effective cooling by rapid heat transfer capability of pulsating jet MQL.

Further, consequence of each input term on chip tool interface temperature is explored using main effects graph, 3-dimensional surface plot and ANOVA. From the graph (Fig. 7), the chip tool interface temperature (T) is augmented by increasing cutting speed, depth of cut and

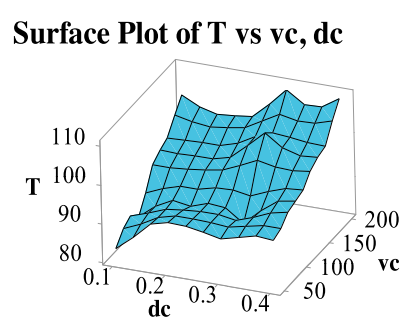

(a)

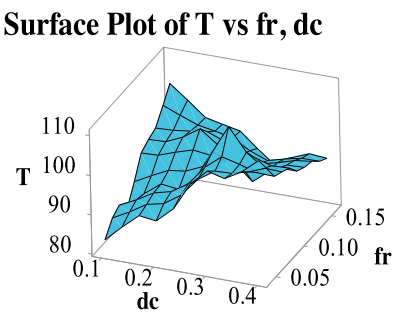

(c)

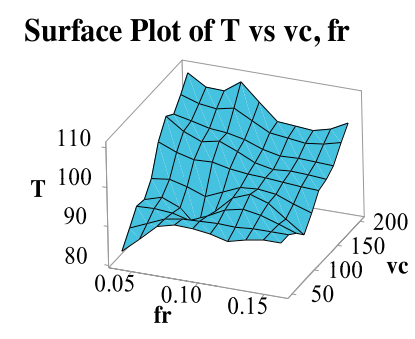

(b)

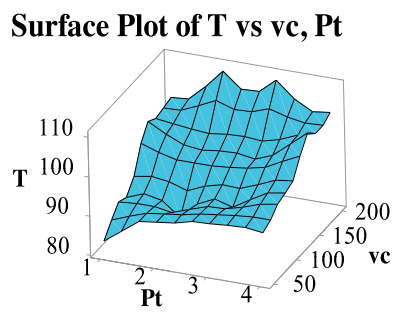

(d)
Fig. 8. Surface plots for chip-tool interface temperature (T).

pulse time while it is dropping with growing feed. Kumar et al. [29] also stated the similar trend of chip-tool interface temperature with growing cutting speed, depth of cut and feed. The tool-chip temperature is reducing with feed rate because material removal rate increases with an increment in feed, thus more heat is carried by chips at faster rate as a result, less amount of heat is present at the tool-chip interface thus tool-chip temperature reduces. Similar results reported by O'Sullivan and Cotterell [40]. Pulsing time of MQL directly control the flow rate of coolant. Lower pulse time exhibited frequent impingement of coolant and vice-versa. Frequent impingement of coolant provided the sufficient amount of coolant during cutting action. In fact, higher frequency of the pulsing jet contributes to higher local Nusselt number and enhances the heat transfer performance [10]. During cutting action some portion of delivered coolant is fall down due gravitational influence while remaining portion is evaporated by evacuating the heat from the cutting zone. However, in $1 \mathrm{~s}$ pulse time, as coolant flow is intermittent with $1 \mathrm{~s}$ of gap hence wastage of coolant by gravitation effect is less relative to higher pulse time. Also, due to impingement of coolant in every second of gap exhibited the better lubrication and cooling effect. Therefore, heat carrying phenomena from the friction region is falling with increasing pulse time as a result chip-tool interface temperature increasing with pulse time. Similar mechanics were also reported by several researchers [10,11]. From the surface plot, combine effect of input terms on chip-tool interface temperature was studied. In Figure 8, surface slope is elevating with rise in cutting speed but effects of depth of cut is less as surface slope is not much changed with leading depth of cut. However, cutting speed introduced the large impact on $\mathrm{T}$ relative to depth of 
Table 3. ANOVA for $\mathrm{T}$.

\begin{tabular}{llrrrrrrr}
\hline Source & DF & \multicolumn{1}{c}{ Seq SS } & Adj SS & Adj MS & \multicolumn{1}{c}{ F } & P & \% cont. & Remarks \\
\hline$d c$ & 3 & 146.188 & 146.188 & 48.729 & 123.11 & 0.001 & 13.99 & Significant \\
$f r$ & 3 & 11.688 & 11.687 & 3.896 & 9.84 & 0.046 & 1.12 & Significant \\
$v c$ & 3 & 807.187 & 807.187 & 269.062 & 679.74 & 0 & 77.28 & Significant \\
$P t$ & 3 & 78.188 & 78.188 & 26.063 & 65.84 & 0.003 & 7.49 & Significant \\
Error & 3 & 1.187 & 1.187 & 0.396 & & & 0.11 & \\
Total & 15 & 1044.437 & & & & & \\
S $=0.629153$ & & $R^{2}=99.89 \%$ & & $R^{2}(\mathrm{adj})=99.43 \%$ & & & & \\
\hline
\end{tabular}

cut (Fig. 8a). Similarly from Figure 8b, dominancy of cutting speed compared to feed rate is clearly observed as surface slope is leading sharply with growing speed. From Figure $8 \mathrm{c}$, it can be stated that the temperature is leading when depth of cut is least and feed increases from low to high. While in other cases trend is not uniform. Similarly, from Figure 8d, surface plot is leading almost uniformly after $100 \mathrm{~m} / \mathrm{min}$ of speed while very marginal increment in surface slope is noticed. However, it can be stated that the cutting speed is more impactful compared to pulsating pulse time towards increment in chip-tool interface temperature. ANOVA statics (Tab. 3), clearly support the trend found in main effects graph and surface plot analysis as contribution of speed $(77.28 \%)$ is largest trailed by depth of cut $(13.99 \%)$, pulse time $(7.49 \%)$ and feed rate $(1.12 \%)$. Based on $95 \%$ of confidence criteria (i.e. $p<0.05)$, all input terms are significant. Das et al. [41] stated that the generation of heat is more sensitive with cutting speed.

\subsection{Inspection of tool-flank face temperature}

Temperatures at flank face directly influence the flank wear, tool life and surface integrity $[42,43]$. Flank face temperature is measured near to the principal cutting edge with help of thermocouple and the average temperature data is considered to be the tool-flank face temperature. Ueda et al. [43] also estimated the tool-flank temperature at main cutting edge of the tool. The measured tool-flank face temperature is listed in Table 2 and found in range of $71-92{ }^{\circ} \mathrm{C}$, which is seemed to be low for hard machining point of view due to efficient cooling and lubricating capability of LRT-30 oil through pulsating MQL mode. Das et al. [44], found tool-tip temperature in the range of $189-373{ }^{\circ} \mathrm{C}$ in dry turning of EN 24 alloy steel which is relatively very larger than the result obtained under pulsating MQL. Main effects plot (Fig. 9), revealed that the tool-flank face temperature (Tf) linearly rises with growing cutting speed and feed. Linearly increment in Tf with speed and depth of cut indicates the dominancy of both terms on Tf. Also, with increase in feed rate and pulse time, $T_{f}$ increased but the rate of increment is slower than cutting speed and depth of cut. Flank face temperature is increasing with feed rate due to increasing contact area between tool and workpiece, as a result, friction between tool-work increases which in turn enhances the cutting temperature [45]. Surface plots (Fig. 10) also signified the same trend of increment in Tf as surface slope increases

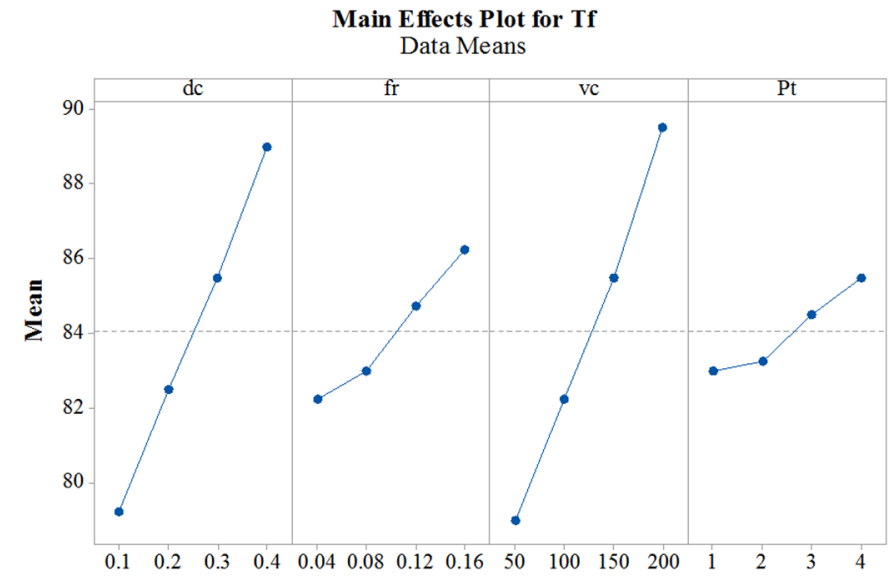

Fig. 9. Influence of input terms on Tf.

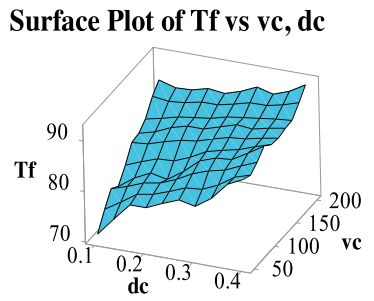

(a)

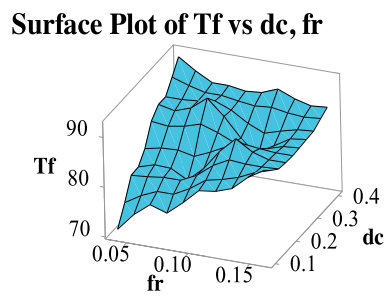

(c)

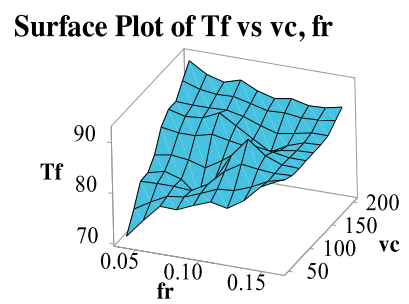

(b)

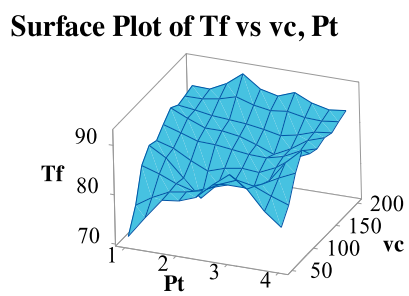

(d)
Fig. 10. Surface plots for flank face temperature (Tf).

sharply with increase in speed and depth of cut. Also, ANOVA report (Tab. 4) analytically confirmed the dominancy of speed $(47.77 \%)$ and depth of cut $(41.06 \%)$ on to the $\mathrm{T}_{\mathrm{f}}$ relative to feed $(7.63 \%)$ and pulse time $(3.19 \%)$. All input terms seem to be noteworthy at $95 \%$ of confidence 
Table 4. ANOVA for Tf.

\begin{tabular}{llrrrrrrr}
\hline Source & DF & \multicolumn{1}{c}{ Seq SS } & Adj SS & Adj MS & \multicolumn{1}{c}{ F } & P & \% cont. & Remarks \\
\hline$d c$ & 3 & 208.188 & 208.188 & 69.396 & 123.37 & 0.001 & 41.06 & Significant \\
$f r$ & 3 & 38.687 & 38.688 & 12.896 & 22.93 & 0.014 & 7.63 & Significant \\
$v c$ & 3 & 242.187 & 242.187 & 80.729 & 143.52 & 0.001 & 47.77 & Significant \\
$P t$ & 3 & 16.188 & 16.188 & 5.396 & 9.59 & 0.048 & 3.19 & Significant \\
Error & 3 & 1.688 & 1.688 & 0.563 & & & \\
Total & 15 & 506.938 & & & & & \\
S $=0.75$ & & $R^{2}=99.67 \%$ & & $R^{2}(\operatorname{adj})=98.34 \%$ & & & \\
\hline
\end{tabular}
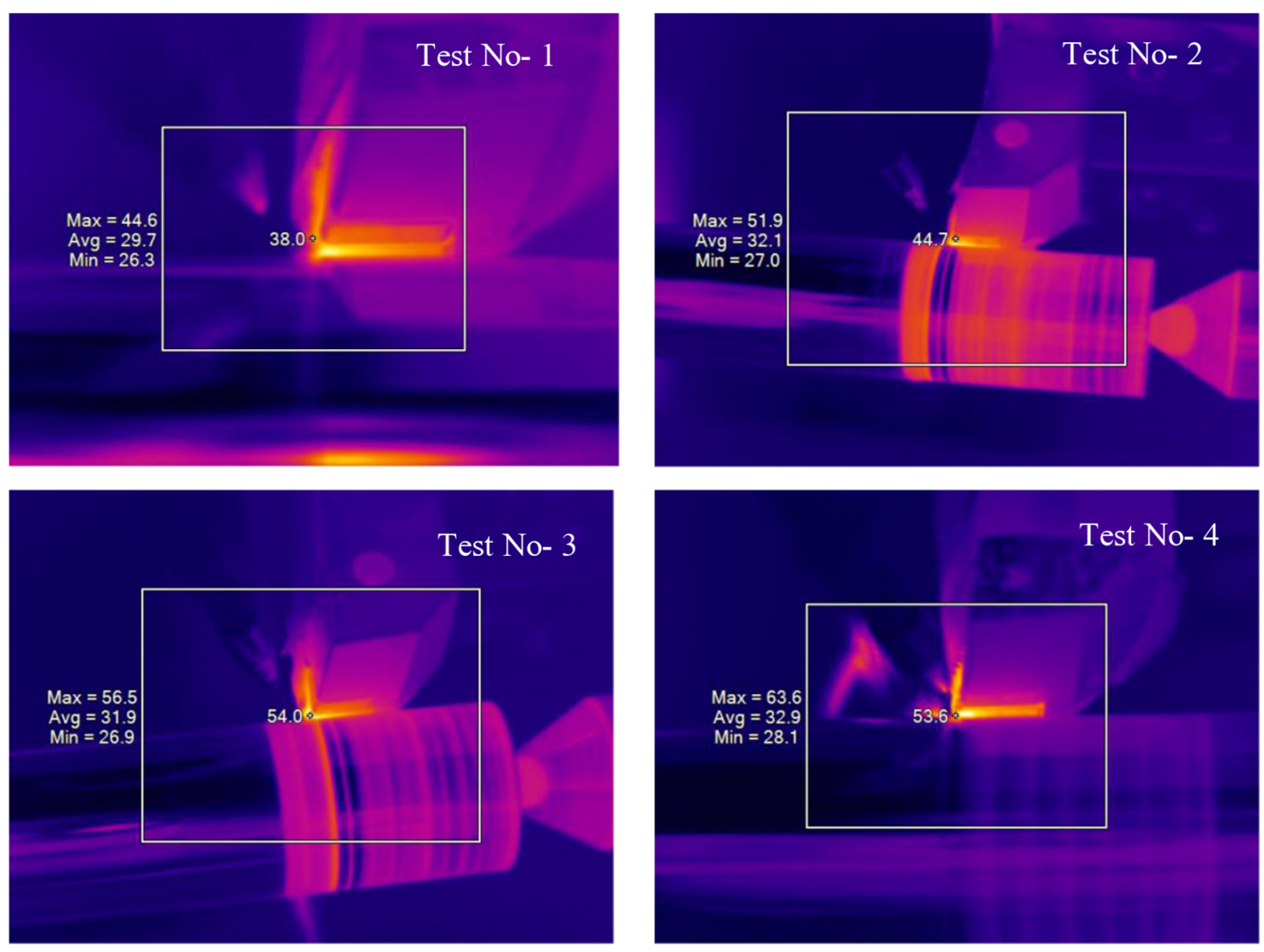

Fig. 11. Thermal image of the machined work surface temperature (Tw).

criteria $[45,46]$. Several researchers were stated that the cutting speed was largely influenced to the tool-flank temperature $[47,48]$.

\subsection{Inspection of machined work surface temperature}

In this experimental investigation, the machined work surface temperature (surface close to tool-work contact) is measured with help of infrared camera and thermal images for test no. 1 to 4 are located in Figure 11. Maximum temperature of the selected region as visible in Figure 11 is taken as the machined work surface temperature and based on this, the temperature value of machined work surface for all 16 tests are listed in Table 2. As work surface temperature significantly affects the surface integrity of the finished surface of the workpiece therefore its analysis is noteworthy for hard machining $[45,49]$. The work surface temperature varies from $44.6^{\circ} \mathrm{C}$ to $91^{\circ} \mathrm{C}$. Lowest temperature $\left(44.6^{\circ} \mathrm{C}\right)$ noticed at lowest magnitude of all input parameters (run 1) while largest temperature exhibited at larger depth of cut $(0.4 \mathrm{~mm})$ and larger speed $(200 \mathrm{~m} / \mathrm{min})$ cutting terms conditions (run 13).

From the graphical plot (Fig. 12) Tw increases linearly when depth of cutting changing from 0.1 to $0.4 \mathrm{~mm}$. Also, significant increment in $\mathrm{Tw}$ is observed with leading values of speed. Effects of feed and pulse time on $\mathrm{Tw}$ is marginal only as graph varies along mean line. Similar observations are reported through surface plot (Fig. 13) as surface slope increases with depth of cutting and speed while with variation in feed and pulse time surface slop is uneven thus 
Table 5. ANOVA for Tw.

\begin{tabular}{llrrrrrrl}
\hline Source & DF & \multicolumn{1}{c}{ Seq SS } & Adj SS & Adj MS & \multicolumn{1}{c}{ F } & \multicolumn{1}{l}{ P } & \% cont. & Remarks \\
\hline$d c$ & 3 & 2436.49 & 2436.49 & 812.16 & 76.89 & 0.002 & 80.40 & Significant \\
$f r$ & 3 & 85.69 & 85.69 & 28.56 & 2.7 & 0.218 & 2.82 & Insignificant \\
$v c$ & 3 & 444.47 & 444.47 & 148.16 & 14.03 & 0.029 & 14.67 & Significant \\
$P t$ & 3 & 32.11 & 32.11 & 10.7 & 1.01 & 0.496 & 1.05 & Insignificant \\
Error & 3 & 31.69 & 31.69 & 10.56 & & & 1.05 & \\
Total & 15 & 3030.44 & & & & & & \\
S $=3.24997$ & & $R^{2}=98.95 \%$ & & $R^{2}(\mathrm{adj})=94.77 \%$ & & & & \\
\hline
\end{tabular}

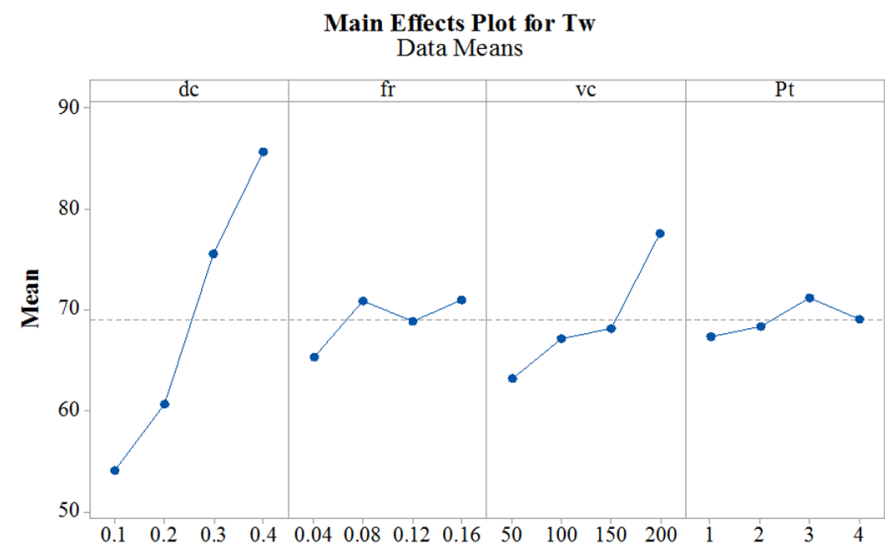

Fig. 12. Influence of input terms on $T_{w}$.

seems to be non-relevant. ANOVA statics (Tab. 5) supports the trend observed in main effects plot and surface plot as depth of cut contributed larger impact with $80.40 \%$ weightage followed by cutting speed (14.67\%), feed $(2.82 \%)$ and pulse time $(1.05 \%)$. Also, taking $95 \%$ of confidence standard, only depth of cut and cutting speed are significant terms towards Tw, while feed and pulse time are exhibiting any relevant impact.

\subsection{Prediction by linear regression}

Linear regression modelling (LRM) is implemented to predict the individual output data [50,51]. Minitab 17 is utilized to accomplish the LRM. The predicted equation for chip-tool interface temperature (T), machined work surface temperature (Tw) and tool-flank face temperature (Tf) is listed in Equations (1), (2) and (3) correspondingly. The term $R^{2}$ in predicted equation is signifies the deviation of fitted data from actual data, $R^{2}$ (adj) data is necessary once the model is being compared and verified by a dissimilar data set while $R^{2}$ (Pred) shows how close model foretell output for new observations [52]. The developed LRM indicates that the $R^{2}$ for each model is close to 1 (i.e. $100 \%$ ), while $R^{2}$ (adj) and $R^{2}$ (pred) are also close to $R^{2}$ and unity. However, the developed predicted models are valid and significant. Normal probability plot for chip-tool interface temperature $(\mathrm{T})$, flank surface temperature (Tf) and work surface temperature (Tw), (Fig. 14) revealed that the residual value lie proximal to the mean line. This
Surface Plot of Tw vs dc, vc

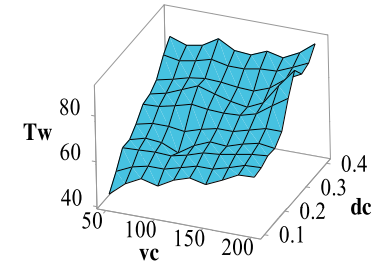

(a)

Surface Plot of Tw vs dc, fr

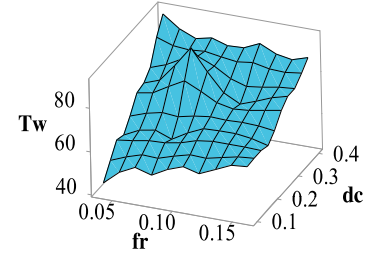

(c)

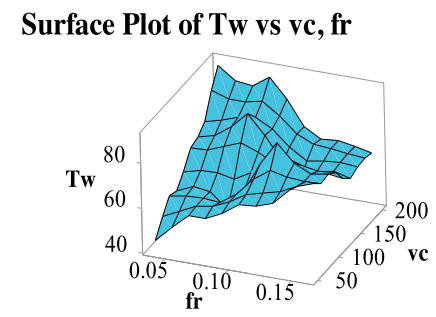

(b)

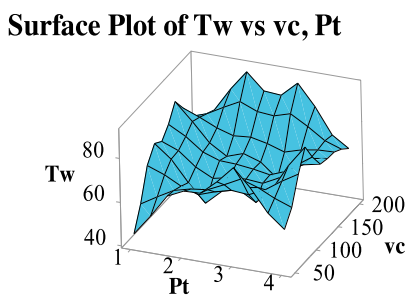

(d)
Fig. 13. Surface plots for machined work surface temperature $(\mathrm{Tw})$.

implies that the recognized models are noteworthy.

$$
\begin{aligned}
& \mathrm{T}=71.19+26.75 \mathrm{dc}-18.1 \mathrm{fr}+0.1215 \mathrm{Vc}+1.975 \mathrm{Pt} \\
& \mathrm{R}^{2}=92.85 \% \quad \mathrm{R}^{2}(\mathrm{adj})=90.25 \% \quad \mathrm{R}^{2}(\text { pred })=85.91 \%
\end{aligned}
$$

$\mathrm{Tf}=61.688+32.25 \mathrm{dc}+34.38 \mathrm{fr}+0.06950 \mathrm{Vc}+0.875 \mathrm{Pt}$ $\mathrm{R}^{2}=99.15 \% \quad \mathrm{R}^{2}(\operatorname{adj})=98.85 \% \quad \mathrm{R}^{2}($ pred $)=98.19 \%$

$$
\begin{aligned}
& \mathrm{Tw}=24.86+109.33 \mathrm{dc}+37.8 \mathrm{fr}+0.0881 \mathrm{vc}+0.813 \mathrm{Pt} \\
& \mathrm{R}^{2}=93.65 \% \quad \mathrm{R}^{2}(\mathrm{adj})=91.33 \% \quad \mathrm{R}^{2}(\text { pred })=88.17 \%
\end{aligned}
$$

Further, the predicted data for each model is compared with experimental value as shown in Figure 15, and found to be very close with experimental value. To get the mean 
Normal Probability Plot

(response is T)

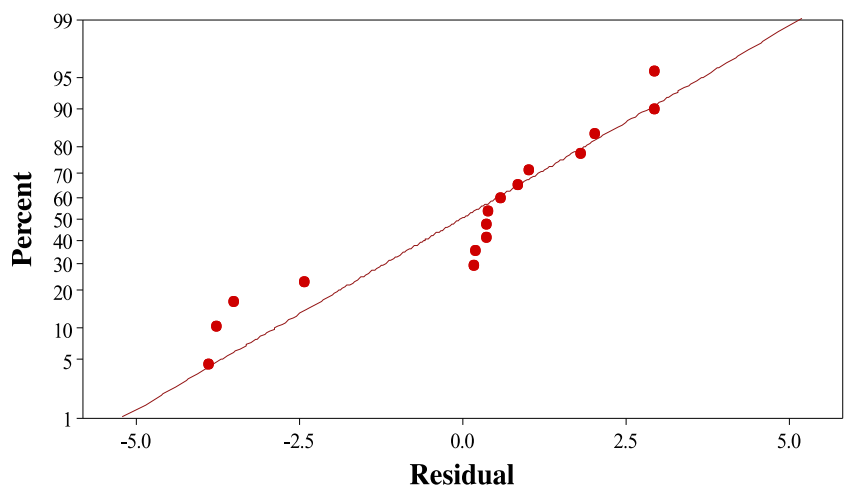

(a)
Normal Probability Plot

(response is Tf)

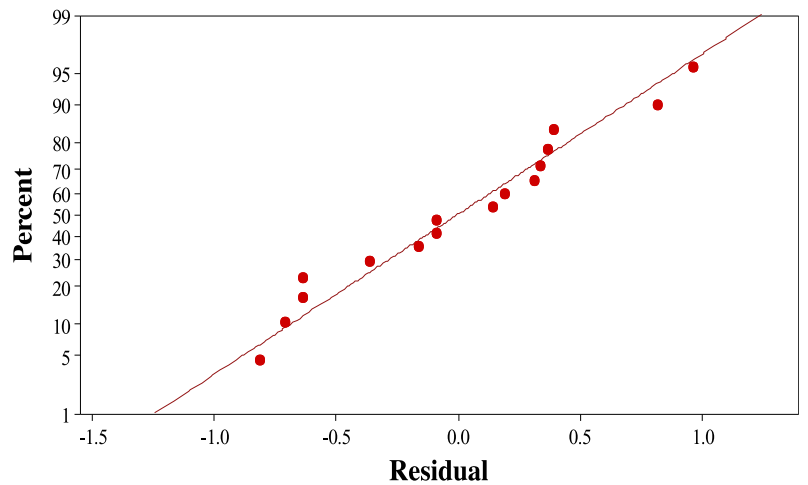

(b)

Normal Probability Plot

(response is Tw)

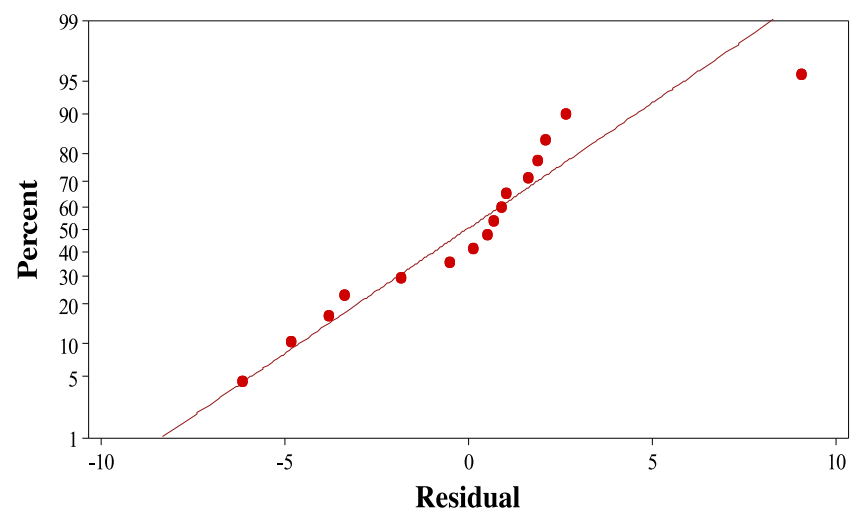

(c)

Fig. 14. Normal Probability graphs for (a) T, (b) Tf and (c) Tw.

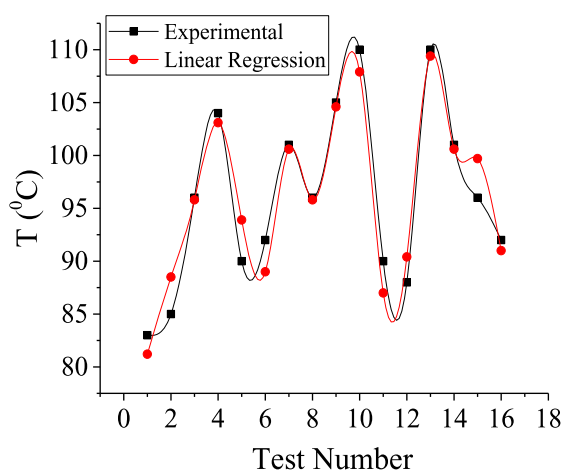

(a)

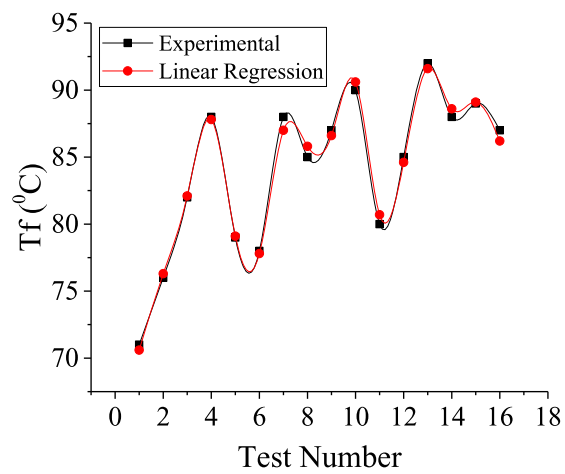

(b)

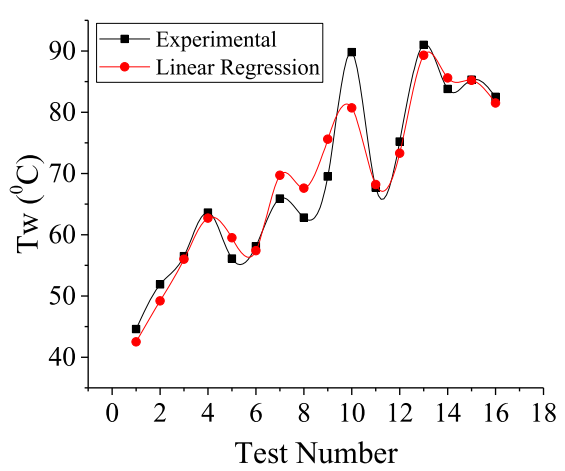

(c)

Fig. 15. Experimental vs. predicted results (a) T (b) Tf and (c) Tw. 
absolute error (MAE) between predicted and the experimental value for each response, the Equation (4) is utilized. The MAE for $\mathrm{T}$, Tf, and $\mathrm{Tw}$ is computed as $1.848 \%$, $0.542 \%$, and $3.766 \%$ individually.

$$
\operatorname{MAE}(\%)=\frac{1}{n}\left[\sum_{i=1}^{n}\left(\frac{\mid \text { experimental }- \text { predicted } \mid}{\text { predicted }}\right) 100\right]
$$

\subsection{WPCA optimization}

The augmentation of Principal Components Analysis (PCA) is known as Weighted Principal Components Analysis (WPCA). Herein, the principal components (individual variables) are generated by applying the multivariate approach as linear amalgamations of the original correlated factors [52]. Generally, the proposed WPCA not only reduces the complexity and uncertainty related to the Taguchi method, but also prevail over the inadequacies of the PCA method. In WPCA analysis, all components are acquired into deliberation so as to enlighten total variation in every response outputs. This utilizes the explicated variations of the weight to merge all principal components so as to find a multi-response performance index (MPI). Afterward, the optimal combination of levels or factors will be obtained [53]. The weighted principal component analysis (WPCA) along with combined-quality-loss (CQL) concept is utilized for the optimization of multiple characteristics and after that CQL has been enhanced utilizing Taguchi technique. At last, CQL and its S/N ration are utilized to find the ideal cutting parameters to achieve the desired quality output. The proposed technique for WPCA along with CQL is a superlative strategy for finding the ideal input cutting parameters for the multifarious multiple responses compared to other approaches [54].

All the measured responses were reflected in this analysis, for instance, T, Tf, and Tw have their individual impact on the quality of a manufactured product. Thus, it is significant to optimize the aforementioned response variables concurrently to maintain an optimum balance amid the quality component and machining cost. The investigation considered for the calculation of the composite principal component. The data of individual principal components multiplied by priority weight were appended to evaluate the composite principal component known as MPI- Multi-response performance index. With this, MPI calculated values are maximized using the traditional Taguchi technique. However, it may ensure that MPI value for any trial may assume negative value and it generates a problem when MPI is maximized. In addition, negative values of MPI pose difficulty through the conversion of it into a signal-to-noise ratio. Further, recent analysis commences a combined quality loss (CQL) concept that is nothing except the absolute deviation of MPI since it is an ideal value. Again, the modulus (absolute value) of deviation assists calculation of signal to noise ratio. Finally, the CQL is optimized reduced by Taguchi technique [55-58]. Taguchi technique is inadequate to

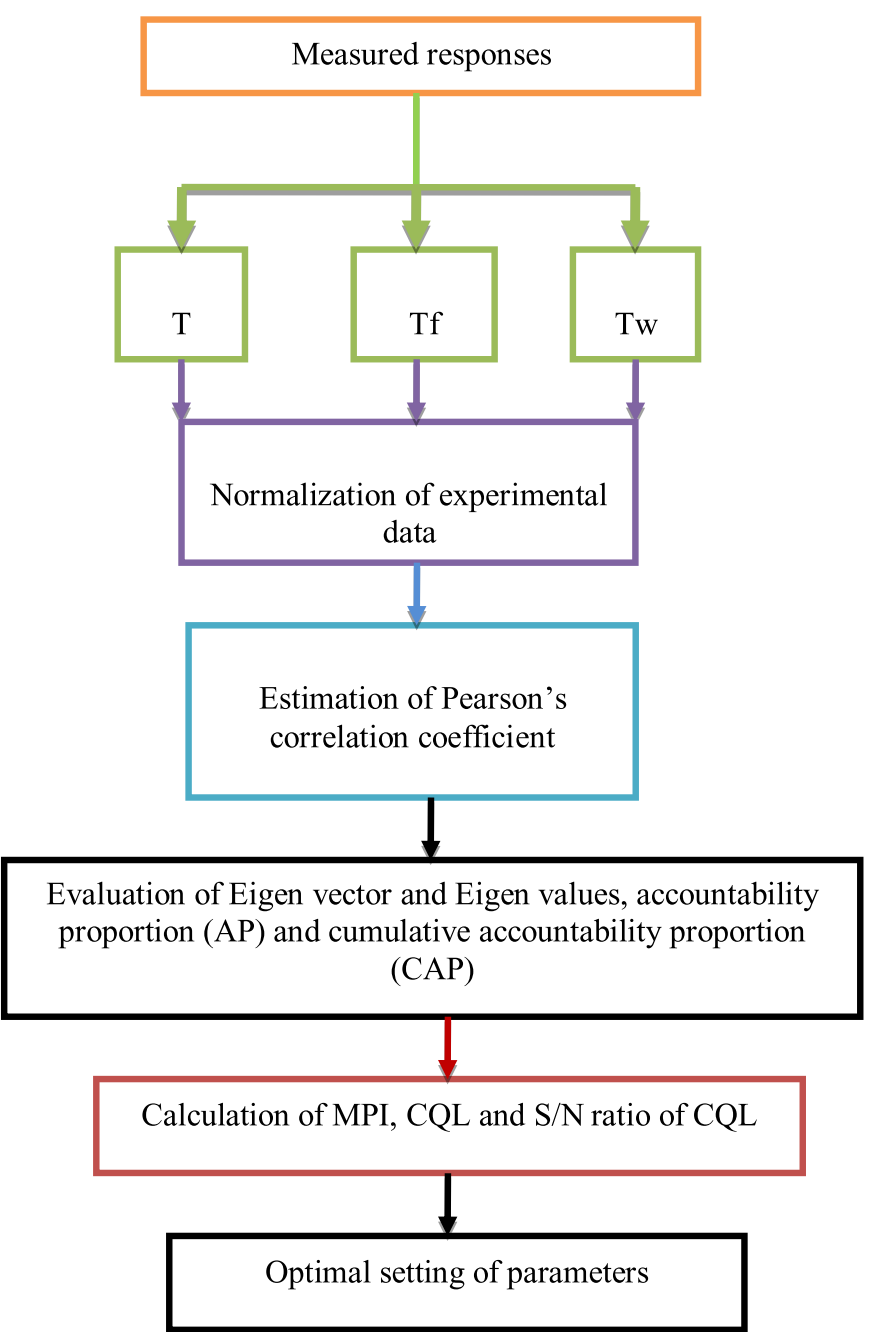

Fig. 16. Procedure for multiple output responses optimization using WPCA.

resolve a multiple response optimization dilemmas. So as to conquer this drawback, this multivariate WPCA technique has been combined with Taguchi approach in the research and the stepwise procedure for multiple output responses optimization using WPCA is given in Figure 16 [58].

The experimental output multi-responses $\mathrm{T}$, Tf, and Tw are normalized considering 'lower-the-better criteria' i.e. $\mathrm{Ki}^{*}(\mathrm{x})=[\min \mathrm{Ki}(\mathrm{x}) / \mathrm{Ki}(\mathrm{x})]$ where, $\mathrm{Ki}^{*}(\mathrm{x})$ is the normalized outcome of the $\mathrm{x}^{\text {th }}$ constituent in the $\mathrm{i}^{\text {th }}$ series and revealed in Table 6 . In addition, Pearson's correlation coefficient between the response factors has been assessed to check the correlation among the measured factors. According to Table 7, it can be visualized that the Pearson's correlation coefficient contains a non-zero data that specifies that the output responses are correlated.

Furthermore, Eigen vector and Eigen values, accountability proportion (AP), and cumulative accountability proportion (CAP) are calculated to eliminate the response correlation and their data are depicted in Table 8 . MINITAB has been used to observe principal component analysis (PCA). Accountability Proportion (AP) of individual principal components is assumed as individual 
priority weights. The individual principal component $\left(\mathrm{PC}_{1}, \mathrm{PC}_{2}\right.$, and $\left.\mathrm{PC}_{3}\right)$ are known as uncorrelated quality indices that are devised by converting into the correlated responses and presented in Table 8.

MPI represents as an overall quality indicator and it is computed by utilizing the Equation (5):

$$
\begin{aligned}
\mathrm{MPI}= & Z 1 \times 1.730+Z 2 \times(-0.009) \\
& +Z 3 \times(-0.067)
\end{aligned}
$$

Table 6. Normalized trial data.

\begin{tabular}{llll}
\hline Run No. & \multicolumn{3}{c}{ Normalized data } \\
\cline { 2 - 4 } & $\mathrm{T}$ & $\mathrm{Tf}$ & $\mathrm{Tw}$ \\
\hline Ideal & 1 & 1 & 1 \\
1 & 1.000 & 1.000 & 1.000 \\
2 & 0.976 & 0.934 & 0.859 \\
3 & 0.865 & 0.866 & 0.789 \\
4 & 0.798 & 0.807 & 0.701 \\
5 & 0.922 & 0.899 & 0.795 \\
6 & 0.902 & 0.910 & 0.768 \\
7 & 0.822 & 0.807 & 0.677 \\
8 & 0.865 & 0.835 & 0.710 \\
9 & 0.790 & 0.816 & 0.642 \\
10 & 0.755 & 0.789 & 0.497 \\
11 & 0.922 & 0.888 & 0.659 \\
12 & 0.943 & 0.835 & 0.593 \\
13 & 0.755 & 0.772 & 0.490 \\
14 & 0.822 & 0.807 & 0.532 \\
15 & 0.865 & 0.798 & 0.523 \\
16 & 0.902 & 0.816 & 0.541 \\
\hline
\end{tabular}

Furthermore, CQL was computed by smaller the better' norm and considers as a single output response. Further to get an optimum set of parameters, Signal to Noise ratio of CQL is estimated considering the 'higher the better' norm. The approximated MPI, CQL, and Signal to Noise ratio of CQL is presented in Table 9.

In addition, the mean $\mathrm{S} / \mathrm{N}$ ratio of $\mathrm{CQL}$ is estimated and listed in Table 9. With reference to Table 10, higher average value of individual input term shows its optimum level and the setting is found as $d c_{1}(0.1 \mathrm{~mm})-f r_{2}$ $(0.08 \mathrm{~mm} / \mathrm{rev})-v c_{2} \quad(100 \mathrm{~m} / \mathrm{min})-P t_{2} \quad(2 \mathrm{~s})$ which is same as run 2 input settings. Additionally, delta (largest value-smallest value) is estimated for individual input term and the rank is estimated as listed in Table 10. Rank order represents the influence impact on the $\mathrm{S} / \mathrm{N}$ ratio of CQL. Term ' $d c$ ' corresponds to the first rank as their delta value is largest (6.034) which confirmed that the impact of ' $d c$ ' on the $\mathrm{S} / \mathrm{N}$ ratio of $\mathrm{CQL}$ is highest among all input terms. The next impactful term on the $\mathrm{S} / \mathrm{N}$ ratio of CQL is found as ' $v c$ ' (4.663) followed by ' $P t$ ' (2.824) and ' $f r$ ' (1.985).

\subsection{Confirmation results}

The attained optimal parameters settings are further used for confirmation trail and the attained value are presented in Table 11. Furthermore, the predicted result is estimated at an optimal setting of parameters using Equation (6).

$$
\gamma_{p}=\gamma_{m}+\sum_{i=1}^{n}\left(\gamma_{0}-\gamma_{m}\right)
$$

Where, $\gamma_{\mathrm{p}}$ indicates the predicted value, $\gamma_{\mathrm{m}}$ signifies the average value of $\mathrm{S} / \mathrm{N}$ ratio, $\gamma_{\mathrm{o}}$ characterizes the

Table 7. Verification of correlation.

\begin{tabular}{llll}
\hline No. & Correlation between & Pearson correlation & Comment \\
response outputs & Tf and T & 0.838 & Both responses are correlated \\
1 & Tf and Tw & 0.858 & Both responses are correlated \\
2 & T and Tw & 0.646 & Both responses are correlated \\
3 & & &
\end{tabular}

Table 8. PCA consequences.

\begin{tabular}{lrrr}
\hline & $\mathrm{PC}_{1}$ & $\mathrm{PC}_{2}$ & $\mathrm{PC}_{3}$ \\
\hline Eigen value & 2.565 & 0.354 & 0.080 \\
& 0.558 & -0.726 & 0.401 \\
Eigen vector & 0.608 & 0.030 & 0.687 \\
& 0.564 & 0.118 & 0.459 \\
AP (Accountability proportion) & 0.855 & 0.973 & 1.000 \\
CAP (Cumulative accountability proportion) & 0.855 & 027 \\
\hline
\end{tabular}


Table 9. Computation of Principal components, MPI, CQL and S/N ratio.

\begin{tabular}{|c|c|c|c|c|c|c|}
\hline \multirow[t]{2}{*}{ Run No. } & \multicolumn{3}{|c|}{ Distinct principal components } & \multirow[t]{2}{*}{ MPI } & \multirow[t]{2}{*}{ CQL } & \multirow[t]{2}{*}{$\mathrm{S} / \mathrm{N}$ Ratio of CQL } \\
\hline & $\mathrm{Z} 1$ & $\mathrm{Z} 2$ & $\mathrm{Z3}$ & & & \\
\hline Ideal & 1.730 & -0.009 & -0.067 & 1.476 & 0.000 & - \\
\hline 1 & 1.730 & -0.009 & -0.067 & 1.476 & 0.000 & - \\
\hline 2 & 1.598 & -0.091 & -0.045 & 1.354 & 0.122 & 18.253 \\
\hline 3 & 1.454 & -0.059 & -0.022 & 1.236 & 0.241 & 12.372 \\
\hline 4 & 1.331 & -0.073 & -0.002 & 1.130 & 0.347 & 9.202 \\
\hline 5 & 1.509 & -0.096 & -0.022 & 1.279 & 0.198 & 14.080 \\
\hline 6 & 1.490 & -0.100 & 0.008 & 1.262 & 0.214 & 13.387 \\
\hline 7 & 1.331 & -0.107 & 0.000 & 1.125 & 0.351 & 9.091 \\
\hline 8 & 1.391 & -0.115 & -0.010 & 1.175 & 0.301 & 10.431 \\
\hline 9 & 1.299 & -0.109 & 0.036 & 1.099 & 0.377 & 8.466 \\
\hline 10 & 1.181 & -0.183 & 0.095 & 0.991 & 0.486 & 6.272 \\
\hline 11 & 1.426 & -0.190 & 0.032 & 1.197 & 0.279 & 11.092 \\
\hline 12 & 1.369 & -0.252 & 0.012 & 1.141 & 0.336 & 9.486 \\
\hline 13 & 1.167 & -0.188 & 0.084 & 0.978 & 0.499 & 6.044 \\
\hline 14 & 1.249 & -0.207 & 0.066 & 1.046 & 0.431 & 7.315 \\
\hline 15 & 1.262 & -0.245 & 0.046 & 1.052 & 0.425 & 7.441 \\
\hline 16 & 1.304 & -0.259 & 0.037 & 1.086 & 0.391 & 8.168 \\
\hline
\end{tabular}

Table 10. Mean S/N ratio of CQL.

\begin{tabular}{|c|c|c|c|c|c|c|c|c|}
\hline \multirow[t]{2}{*}{ Symbol } & \multirow{2}{*}{$\begin{array}{l}\text { Input cutting } \\
\text { parameters }\end{array}$} & \multicolumn{4}{|c|}{ Mean S/N ratio } & \multirow{2}{*}{$\begin{array}{l}\text { Optimal } \\
\text { settings }\end{array}$} & \multirow[t]{2}{*}{ Delta } & \multirow[t]{2}{*}{ Rank } \\
\hline & & Level-1 & Level-2 & Level-3 & Level-4 & & & \\
\hline$d c$ & Depth of cut & 13.276 & 11.747 & 8.829 & 7.242 & 1 & 6.034 & 1 \\
\hline$f r$ & Feed rate & 9.530 & 11.307 & 9.999 & 9.321 & 2 & 1.985 & 4 \\
\hline$v c$ & Cutting speed & 10.882 & 12.315 & 9.646 & 7.652 & 2 & 4.663 & 2 \\
\hline$P t$ & Pulse time & 8.630 & 11.450 & 10.223 & 9.624 & 2 & 2.824 & 3 \\
\hline
\end{tabular}

Table 11. Consequences of confirmation experiment for multiple-responses.

\begin{tabular}{llll}
\hline & Initial setting $d c_{2}-f r_{4}-v c_{3}-P t_{2}$ & \multicolumn{2}{c}{ Optimal setting $d c_{1}-f r_{2}-v c_{2}-P t_{2}$} \\
\cline { 2 - 3 } & & Prediction & Experiment \\
\hline $\mathrm{T}\left({ }^{\circ} \mathrm{C}\right)$ & 96 & & 85 \\
$\mathrm{Tf}\left({ }^{\circ} \mathrm{C}\right)$ & 85 & & 76 \\
$\mathrm{Tw}\left({ }^{\circ} \mathrm{C}\right)$ & 62.8 & & 51.9 \\
$\mathrm{CQL}$ & 0.301 & 17.197 & 0.122 \\
$\mathrm{~S} / \mathrm{N}$ Ratio of CQL $(\mathrm{dB})$ & 10.431 & & 18.253 \\
& Gain in S/N ratio of CQL $=7.822$ & & \\
\hline
\end{tabular}

optimal level S/N ratio, 'i' represent the number of input term $(1 \ldots \ldots n)$. and $n$ is the number of important design factors.

The initial $\mathrm{S} / \mathrm{N}$ ratio of $\mathrm{CQL}$ is considered from the experimental trial (run 8). This is contrasted with results obtained at optimum settings (run 2). According to comparative statics, the gain in the $\mathrm{S} / \mathrm{N}$ ratio of $\mathrm{CQL}$ is computed as 10.431 i.e. it is about $75 \%$ larger than the initial parameter setting. However, it can be clearly stated that the current WPCA optimization methodology is proficiently and effectually optimize the multiple output responses. 


\section{Conclusion}

This work presented a novel study on temperature evolved during finish hard turning operation of AISI 4340 heat treated steel using multi-layered coated carbide insert under pulsating MQL environment. Temperatures are measured at three different locations namely chip-tool interface, flank face, and machined work surface (near to tool-work contact). Thus, chip tool interface temperature $(\mathrm{T})$, flank face temperature (Tf) and machined work surface temperature ( $\mathrm{Tw})$ are studied with help of main effect plot, 3-Dimensional surface plot and ANOVA. Further, these temperatures are predicted using linear regression, fuzzy logic and ANN approaches. The major findings are summarized as follows:

- Lower pulse time exhibits frequent impingement of coolant as compared to higher pulse time. Frequent impingement of coolant at the machining zone provides the sufficient amount of coolant during cutting action, so the performance of lower pulse time is superior as compared to higher pulse time. Considering average temperature statics of all temperature, chip-tool interface temperature $(\mathrm{T})$ is $14.42 \%$ greater than flank face temperature (Tf) and $39.36 \%$ larger than machined work-surface temperature (Tw), while flank face temperature ( $\mathrm{Tf}$ ) is $21.79 \%$ greater than machined worksurface temperature $\left(\mathrm{T}_{\mathrm{w}}\right)$.

- Chip tool interface temperature $(\mathrm{T})$ is found in the range of $83-110^{\circ} \mathrm{C}$, which is quite low for finish hard turning concern. The magnitude of this temperature is strengthening with leading cutting speed, depth of cut and pulse time, while it is dropping with increase in feed. From the surface plot the combined effect of input parameters on chip tool interface temperature was studied. The results indicate that cutting speed is the most dominating machining parameter followed by depth of cut, pulse time and feed rate. ANOVA statics reported that the cutting speed (77.28\%) largely affect the chip tool interface temperature trailed by depth of cut $(13.99 \%)$, pulse time $(7.49 \%)$ and feed rate $(1.12 \%)$. Based on $95 \%$ of confidence criteria (i.e. $p<0.05$ ), all input terms are significant.

- Flank face temperature (Tf) is found in the range of $71-92{ }^{\circ} \mathrm{C}$, which is seemed to be low for hard machining point of view due to excellent cooling and lubricating capability of LRT-30 oil under pulsating MQL environment. This temperature is leading with cutting speed and depth of cut while pulse time and feed have less influence on it. ANOVA report indicates the superior effect of cutting speed $(47.77 \%)$ and depth of cut $(41.06 \%)$ on $\mathrm{Tf}$ compared to feed $(7.63 \%)$ and pulse time (3.19\%). All input terms seem to be noteworthy at $95 \%$ of confidence criteria.

- The machined work surface temperature $(\mathrm{Tw})$ is found in the range of $44.6-91^{\circ} \mathrm{C}$ and it is highly influenced by depth of cut trailed by cutting speed. ANOVA report indicates that the depth of cut is the most influencing term with $80.40 \%$ weightage trailed by cutting speed $(14.67 \%)$, feed $(2.82 \%)$ and pulse time (1.05\%). only depth of cut and cutting speed are noteworthy at $95 \%$ of confidence criteria.

- Linear regression technique exhibited good prediction as MAE for responses T, Tf, and Tw is found as $1.848 \%$, $0.542 \%$, and $3.766 \%$ individually.

- WPCA optimization results shows the setting of parameters as $d c_{1}(0.1 \mathrm{~mm})-f r_{2}(0.08 \mathrm{~mm} / \mathrm{rev})-v c_{2}$ $(100 \mathrm{~m} / \mathrm{min})-P t_{2}(2 \mathrm{~s})$. At this setting, the gain in the $\mathrm{S} / \mathrm{N}$ ratio of CQL is computed as 10.431 i.e. it is $75 \%$ larger than the initial considered setting. However, it can be stated that the WPCA optimization methodology is proficiently and effectually optimize the multiple output responses.

From comprehensive experimental investigation and analysis under time controlled pulse MQL cutting environment in finish hard turning of AISI 4340-grade steel, it was revealed that CVD multi-layered $\mathrm{Al}_{2} \mathrm{O}_{3}$ coated carbide insert performs exceedingly well and may be considered as novel alternative over conventional cooling methods in hard turning that is being usual practice in shop floors.

Authors are very thankful to KIIT Deemed to be university for providing the experimental facilities to accomplish the current research

\section{References}

[1] C. Bruni, F.F. Gabrielli, M. Simoncini, Effect of the lubrication-cooling technique, insert technology and machine bed material on the workpart surface finish and tool wear in finish turning of AISI 420B, Int. J. Mach. Tools Manuf. 46, 1547-1554 (2006)

[2] R. Kumar, A.K. Sahoo, P.C. Mishra, R.K. Das, S. Roy, ANN Modeling of Cutting Performances in Spray Cooling Assisted Hard Turning, Mater. Today Proc., 18482-18488 (2018)

[3] P.J. Liew, A. Shaaroni, N.A.C. Sidik, J. Yan, An overview of current status of cutting fluids and cooling techniques of turning hard steel, Int. J. Heat. Mass Transf. 114, 380-394 (2017)

[4] R. Kumar, A.K. Sahoo, P.C. Mishra, R.K. Das, An investigation to study the wear characteristics and comparative performance of cutting inserts during hard turning, Int. J. Mach. Mach. Mater. 20-24 (2018). https://doi.org/ 10.1504/IJMMM.2018.094730

[5] S. Chinchankar, S.K. Choudhury, Machining of hardened steel experimental investigations, performance modeling and cooling techniques: a review, Int. J. Mach. Tool Manufact. 89, 95-109 (2015)

[6] R. Kumar, A.K. Sahoo, P.C. Mishra, R.K. Das, M. Ukamanal, Experimental investigation on hard turning using mixed ceramic insert under accelerated cooling environment, Int. J. Ind. Eng. Comput. 9, 509-522 (2018)

[7] V.S. Sharma, G.R. Singh, K. Sorby, A Review on Minimum Quantity Lubrication for Machining Processes, Mater. Manuf. Process. 30, 935-953 (2015)

[8] R.K. Das, A.K. Sahoo, R. Kumar, S. Roy, P.C. Mishra, T. Mohanty, MQL assisted cleaner machining using PVD TiAlN coated carbide insert: comparative assessment, Indian J. Eng. Mater. Sci. 26, 311-325 (2019) 
[9] R.K. Das, A.K. Sahoo, R. Kumar, A. Panda, Performances of time-controlled pulse minimum quantity lubrication in machining of hard to cut material: a brief review, Mater. Today Proc. 23, 545-548 (2020)

[10] M. Mia, M.H. Razi, I. Ahmad, R. Mostafa, S.M. Rahman, D. H. Ahmed, N.R. Dhar, Effect of time-controlled MQL pulsing on surface roughness in hard turning by statistical analysis and artificial neural network, Int. J. Adv. Manufact. Technol. 91, 3211-3223 (2017)

[11] M. Al Bashir, M. Mia, N.R. Dhar, Effect of pulse Jet MQL in surface milling of hardened steel, J. Mech. Eng. 45, 67-72 (2016)

[12] A. Shokrani, V. Dhokia, S.T. Newman, Environmentally conscious machining of difficult-to-machine materials with regard to cutting fluids, Int. J. Mach. Tool Manu. 57, 83-101 (2012)

[13] R. Padmini, P.V. Krishna, G.K.M. Rao, Effectiveness of vegetable oil based nanofluids as potential cutting fluids inturning AISI 1040 steel, Tribol. Int. 94, 490-501 (2016)

[14] A. Das, S.K. Patel, B.B. Biswal, S.R. Das, Performance evaluation of aluminium oxide nano particles in cutting fluid with MQL technique in turning of hardened AISI 4340 alloy steel, Int. J. Eng. Sci. Technol. (2019) https://doi.org/ 10.24200/SCI.2019.51223.2069

[15] S.U. Gunjal, S.B. Sanap, N.G. Patil, Role of cutting fluids under minimum quantity lubrication An experimental investigation of chip thickness, Mater. Today Proc. (2020) https://doi.org/10.1016/j.matpr.2020.01.090

[16] A. Das, S.K. Patel, B.B. Biswal, N. Sahoo, A. Pradhan, Performance evaluation of various cutting fluids using MQL technique in hard turning of AISI 4340 alloy steel, Measurement 150, 107079 (2020)

[17] S. Chinchanikar, S.K. Choudhury, Evaluation of chip-tool interface temperature: effect of tool coating and cutting parameters during turning hardened AISI 4340 ateel, Procedia. Munuf. Sci. 6, 996-1005 (2014)

[18] N.A. Abukhshim, P.T. Mativenga, M.A. Sheikh, Heat generation and temperature prediction in metal cutting: a review and implications for high speed machining, Int. J. Mach. Tool Manu. 46, 782-800 (2006)

[19] R. Komanduri, Z.B. Hou, A review of the experimental techniques for the measurement of heat and temperatures generated in some manufacturing processes and technology, Tribol. Int. 34, 653-682 (2001)

[20] D.O. Sullivan, M. Cotterell, Temperature measurement in single point turning, J. Mater. Process. Tech. 118, 301-308 (2001)

[21] A. Basti, T. Obikawa, J. Shinozuka, Tools with built-in thin film thermocouple sensors for monitoring cutting temperature, Int. J. Mach. Tool Manuf. 47, 793-798 (2007)

[22] S. Chinchanikar, S.K. Choudhury, A.P. Kulkarni, Investigation of chip-tool interface temperature during turning of hardened AISI 4340 alloy steel using multi-layer coated carbide inserts, Adv. Mat. Res. 701, 354-358 (2013)

[23] A. Kus, Y. Isik, M.C. Cakir, S. Coskun, K. Özdemir, Thermocouple and infrared sensor-based measurement of temperature distribution in metal cutting, Sensors 15, 1274-1291 (2015)

[24] L. Chen, B.L. Tai, R.G. Chaudhari, X. Song, A.J. Shih, Machined surface temperature in hard turning, Int. J. Mach. Tool Manuf. 121, 10-21 (2017)
[25] C.E. Leshock, Y.C. Shin, Investigation on cutting temperature in turning by a tool-work thermocouple technique, J. Manuf. Sci. Eng. 119, 502-508 (1997)

[26] M.J. Hadad, T. Tawakoli, M.H. Sadeghi, B. Sadeghi, Temperature and energy partition in minimum quantity lubrication-MQL grinding process, Int. J. Mach. Tool Manuf. 54-55, 10-17 (2012)

[27] M.C. Santos Jr, A.R. Machado, M.A.S. Barrozo, L.M. Neto, E.A.A. Coelho, Influence of thermoelectric junctions on the electrical signals generated by the tool-workpiece thermocouple system in machining, Measurement 46, 2540-2546 (2013)

[28] M.A. Huda, K. Yamada, A. Hosokawa, T. Ueda, Investigation of temperature at tool-chip interface in turning using two-color pyrometer, J. Manuf. Sci. Eng. 124, 200-207 (2002)

[29] R. Kumar, A.K. Sahoo, P.C. Mishra, R.K. Das, Comparative investigation towards machinability improvement in hard turning using coated and uncoated carbide inserts: part I experimental investigation, Adv. Manuf. 6, 52-70 (2018)

[30] R. Kumar, A.K. Sahoo, P.C. Mishra, R.K. Das, Measurement and machinability study under environmentally conscious spray impingement cooling assisted machining, Measurement 135, 913-927 (2019)

[31] R. Kumar, A.K. Sahoo, P.C. Mishra, R.K. Das, Influence of $\mathrm{Al}_{2} \mathrm{O}_{3}$ and $\mathrm{TiO}_{2}$ nanofluid on hard turning performance, Int. J. Adv. Manuf. Syst. 106, 2265-2280 (2020)

[32] M. Senthilkumar, A. Prabukarthi, V. Krishnaraj, Machining of CFRP/Ti6Al4V stacks under minimal quantity lubricating condition, J. Mech. Sci. Technol. 32, 3787-3796 (2018)

[33] M. Ukamanal, P.C. Mishra, A.K. Sahoo, Effects of spray cooling process parameters on machining performance AISI 316 steel: a novel experimental, Exp. Tech. 44, 19-36 (2020)

[34] M. Gosai, S.N. Bhavsar, Experimental study on temperature measurement in turning operation of hardened steel (EN36), Procedia Technol. 23, 311-318 (2016)

[35] S.D. Ghodam, Temperature measurement of a cutting tool in turning process by using tool work thermocouple, Int. J. Res. Eng. Technol. 03, 831-835 (2014)

[36] M. Sarıkaya, A. Güllü, Multi-response optimization of minimum quantity lubrication parameters using Taguchibased grey relational analysis in turning of difficult-to-cut alloy Haynes 25, J. Clean. Prod. 91, 347-357 (2015)

[37] N. Boubekri, V. Shaikh, Minimum Quantity Lubrication (MQL) in machining: benefits and drawbacks, J. Ind. Intelligent Inform. 3, 205-209 (2015)

[38] R.K. Das, A.K. Sahoo, R. Kumar, A. Panda, Performances of time-controlled pulse minimum quantity lubrication in machining of hard to cut material: a brief review, Mater. Today Proc. 23, 545-548 (2020)

[39] S. Chinchanikar, S.K. Choudhury, Evaluation of chip-tool interface temperature: effect of tool coating and cutting parameters during turning hardened AISI 4340 steel, Procedia. Mater. Sci. 6, 996-1005 (2014)

[40] D. O'Sullivan, M. Cotterell, Temperature measurement in single point turning, J. Mater. Process. Technol. 118, 301-308 (2001)

[41] A. Das, S.K. Patel, T.K. Hotta, B.B. Biswal, Statistical analysis of different machining characteristics of EN-24 alloy steel during dry hard turning with multilayer coated cermet inserts, Measurement 134, 123-141 (2019) 
[42] T. Ueda, A. Hosokawa, K. Oda, K. Yamada, Temperature on flank face of cutting tool in high speed milling, CIRP Annals 50, 37-40 (2001)

[43] T. Ueda, M.A. Huda, K. Yamada, K. Nakayama, H. Kudo, Temperature measurement of CBN tool in turning of high hardness steel, CIRP Annals 48, 63-66 (1999)

[44] A. Das, S.K. Patel, B.B. Biswal, N. Sahoo, A. Pradhan, Performance evaluation of various cutting fluids using MQL technique in hard turning of AISI 4340 alloy steel, Measurement 150, 107079 (2020)

[45] S. Patil, S. Jadhav, S. Kekade, A. Supare, A. Powar, R.K.P. Singh, The influence of cutting heat on the surface Integrity during machining of Titanium Alloy Ti6Al4V, Proced. Manufact. 5, 857-869 (2016)

[46] R. Kumar, A.K. Sahoo, R.K. Das, A.K. Panda, P.C. Mishra, Modelling of flank wear, surface roughness, cutting temperature in sustainable hard turning of AISI D2 steel, Procedia. Manuf. 20, 406-413 (2018)

[47] J. Hou, W. Zhou, H. Duan, G. Yang, H. Xu, N. Zhao, Influence of cutting speed on cutting force, flank temperature, and tool wear in end milling of Ti-6Al-4V alloy, Int. J. Adv. Manuf. Tech. 70, 1835-1845 (2014)

[48] J. Hou, N. Zhao, S. Zhu, Influence of cutting speed on flank temperature during face milling of magnesium alloy, Mater. Manuf. Process. 26, 1059-1063 (2011)

[49] G. Rotella, O.W. Dillon Jr, D. Umbrello, L. Settineri, I.S. Jawahir, The effects of cooling conditions on surface integrity in machining of Ti6Al4V alloy, Int. J. Adv. Manuf. Technol. 71, 47-55 (2014)

[50] O. Pereira, P.C. Català, A. Rodríguez, T. Ostra, J.C. Vivancos, A. Rivero, L.N. Lopez-de-Lacalle, The use of hybrid $\mathrm{CO}_{2}+\mathrm{MQL}$ in machining operations, Procedia. Engg. 132, 492-499 (2015)

[51] A. Pandey, R. Kumar, A.K. Sahoo, A. Paul, A. Panda, Performance analysis of trihexyltetradecylphosphonium chloride ionic fluid under MQL condition in hard turning, Int. J. Automat. Mech. Eng. 17, 7626-7647 (2020)

[52] R. Kumar, A.K. Sahoo, P.C. Mishra, R.K. Das, Comparative study on machinability improvement in hard turning using coated and uncoated carbide inserts: part II modeling, multi-response optimization, tool life, and economic aspects, Adv. Manuf. 6, 155-175 (2018)

[53] A. Nair, S. Kumanan, Multi-performance optimization of abrasive water jet machining of Inconel 617 using WPCA, Mater. Manufact. Process. 32, 693-699 (2017)

[54] H.C. Liao, Multi-response optimization using weighted principal component, Int. J. Adv. Manufact. Technol. 27, 720-725 (2006)

[55] M.R. Ch, V.V.S. Kesava Rao, Application of WPCA \& CQL methods in the optimization of multiple responses, Mater. Today: Proceed. 18, 25-36 (2019)

[56] B.B. Nayak, K. Abhishek, S.S. Mahapatra, D. Das, Application of WPCA based Taguchi method for multiresponse optimization of abrasive jet machining process, Mater. Today: Proceed. 5, 5138-5144 (2018)

[57] R. Kumar, A. Modi, A. Panda, A.K. Sahoo, A. Deep, P.K. Behra, R. Tiwari, Hard turning on JIS S45C structural steel: an experimental, modelling and optimisation approach, Int. J. Automot. Mech. Eng. 16, 7315-7340 (2019)

[58] S. Swain, I. Panigrahi, A.K. Sahoo, A. Panda, R. Kumar, Effect of tool vibration on flank wear and surface roughness during high-speed machining of 1040 steel, J. Fail. Analys. Preven. 20, 976-994 (2020)

Cite this article as: S. Roy, R. Kumar, A.K. Sahoo, A. Pandey, A. Panda, Investigation on hard turning temperature under a novel pulsating MQL environment: An experimental and modelling approach, Mechanics \& Industry 21, 605 (2020) 